May 2002 • NREL/SR-620-32180

\title{
The Implications of Regional Transmission Organization Design for Renewable Energy Technologies
}

Kevin Porter

Exeter Associates, Inc.

Silver Spring, Maryland

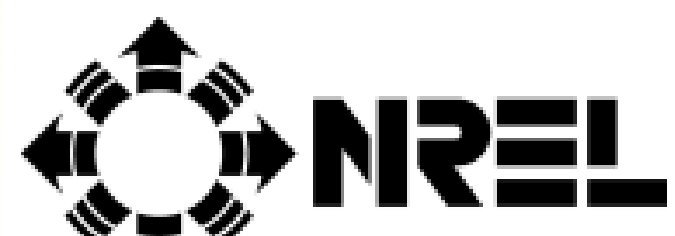

National Renewable Energy Laboratory

1617 Cole Boulevard

Golden, Colorado 80401-3393

NREL is a U.S. Department of Energy Laboratory

Operated by Midwest Research Institute $\bullet$ Battelle $\bullet$ Bechtel

Contract No. DE-AC36-99-G010337 
May 2002 • NREL/SR-620-32180

\section{The Implications of Regional Transmission Organization Design for Renewable Energy Technologies}

Kevin Porter

Exeter Associates, Inc.

Silver Spring, Maryland

NREL Technical Monitor: Larry Goldstein

Prepared under Subcontract No. KADC-9-24462-08

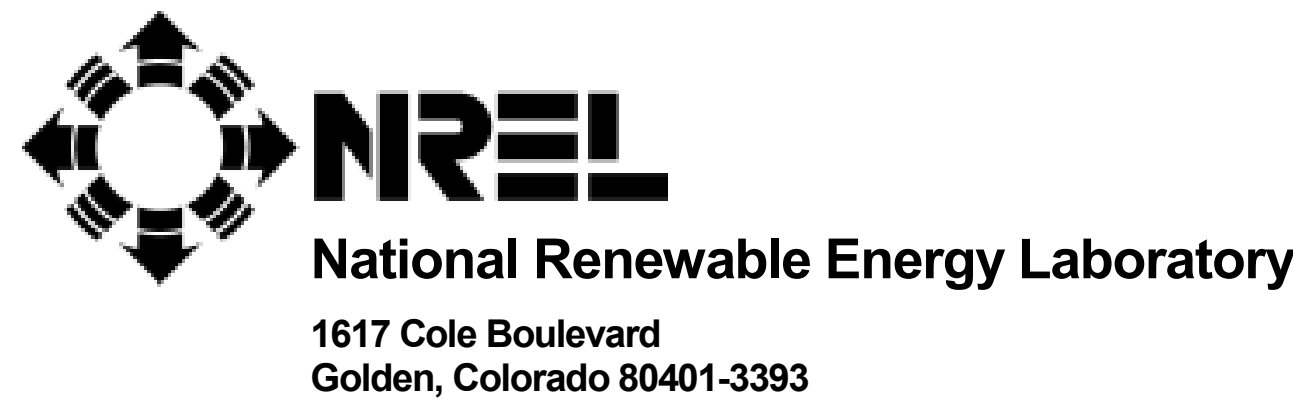

NREL is a U.S. Department of Energy Laboratory

Operated by Midwest Research Institute $\bullet$ Battelle $\bullet$ Bechtel

Contract No. DE-AC36-99-G010337 


\section{NOTICE}

This report was prepared as an account of work sponsored by an agency of the United States government. Neither the United States government nor any agency thereof, nor any of their employees, makes any warranty, express or implied, or assumes any legal liability or responsibility for the accuracy, completeness, or usefulness of any information, apparatus, product, or process disclosed, or represents that its use would not infringe privately owned rights. Reference herein to any specific commercial product, process, or service by trade name, trademark, manufacturer, or otherwise does not necessarily constitute or imply its endorsement, recommendation, or favoring by the United States government or any agency thereof. The views and opinions of authors expressed herein do not necessarily state or reflect those of the United States government or any agency thereof.

Available electronically at http://www.osti.gov/bridge

Available for a processing fee to U.S. Department of Energy

and its contractors, in paper, from:

U.S. Department of Energy

Office of Scientific and Technical Information

P.O. Box 62

Oak Ridge, TN 37831-0062

phone: 865.576.8401

fax: 865.576.5728

email: reports@adonis.osti.gov

Available for sale to the public, in paper, from:

U.S. Department of Commerce

National Technical Information Service

5285 Port Royal Road

Springfield, VA 22161

phone: 800.553.6847

fax: 703.605.6900

email: orders@ntis.fedworld.gov

online ordering: http://www.ntis.gov/ordering.htm

Printed on paper containing at least $50 \%$ wastepaper, including $20 \%$ postconsumer waste 


\section{Table of Contents}

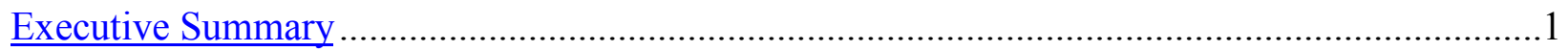

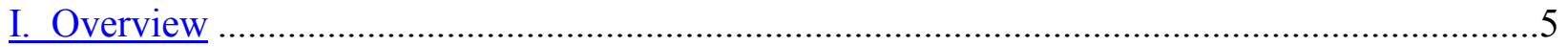

II. Intermittent Renewable Energy Technologies and RTOs .....................................................

Pennsylvania-New Jersey-Maryland Interconnection ISO (PJM) ........................................... 8

Electric Reliability Council of Texas (ERCOT) ISO ………................................................12

Midwest Independent System Operator (Midwest ISO) .........................................................15

New York Independent System Operator (NYISO) ………..................................................2.

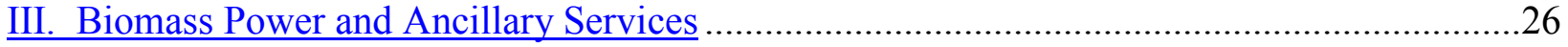

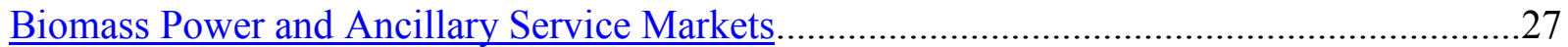

IV. Creating a Northeast-Wide RTO: A Further Look at "Seams" Issues ....................................29

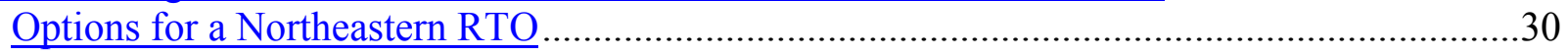

Implications for Renewable Energy Technologies ……...........................................................

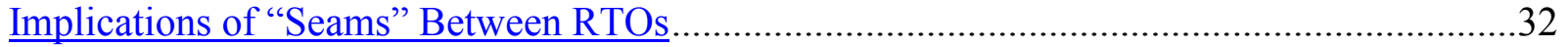

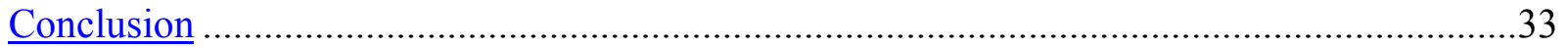

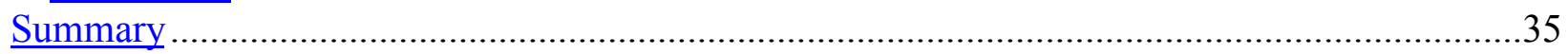

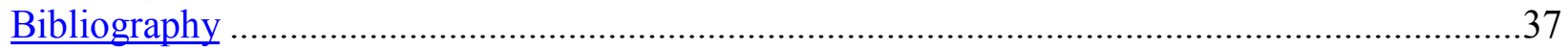

Appendix A: FERC's Required RTO Characteristics and Functions in Order 2000 ...................46

Appendix B: Summaries of the PJM, ERCOT and Midwest ISOs..............................................47

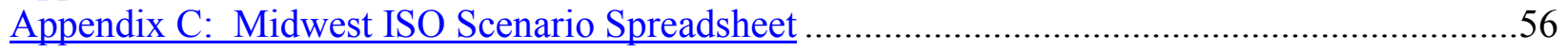

\section{Tables}

Table 1: Scenario Results for Intermittent Renewable Energy Generator in Midwest ISO ........ 18

Table 2: The Three Northeastern Independent System Operators ................................................ 29

\section{Figures}

Figure 1. Proposed and Planned Regional Transmission Organizations ..................................... 5

Figure 2. Map of PJM Control Area …………………............................................................ 10

Figure 3. The Operations of the ERCOT Bilateral Market......................................................... 13

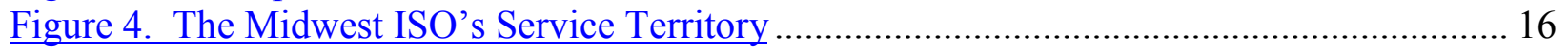

Figure 5. The New York ISO's Zones .................................................................................... 21 


\section{Acknowledgments}

The Implications of Regional Transmission Organization Design For Renewable Energy Technologies was prepared by Kevin Porter of Exeter Associates, Inc. for the National Renewable Energy Laboratory (NREL) and for the Office of Power Technologies (OPT) of the U.S. Department of Energy (DOE). The author would like to thank Larry Goldstein of NREL and Tina Kaarsberg of DOE for the personal and financial support they provided to this project.

This report was inspired by previous work performed by Robert Grace of Sustainable Energy Advantage for the Pace Energy Project, and by discussions with Ryan Wiser of the Ernest Orlando Lawrence Berkeley National Laboratory and David Wooley of the American Wind Energy Association. The author thanks those individuals for their assistance.

Martin Fullenbaum and Steven Estomin of Exeter Associates, Inc.; Jack Cadogan of DOE; Brian Parsons of NREL; and Matthew Kahal, a consultant based in Silver Spring, Maryland; read an early draft of this report and provided very helpful comments and guidance. Chase Kappel, also of Exeter Associates, Inc., provided invaluable research assistance and support. The author also thanks Eric Hirst, a consultant in Oak Ridge, Tennessee; Mark Bolinger and Chris Marnay of the Ernest Orlando Lawrence Berkeley National Laboratory; Lori Bird of NREL; Michael Freeman of the Exelon Power Team; Jim Caldwell of the American Wind Energy Association; Beth Nagusky of the Independent Energy Producers of Maine; and Eric Schubert of the Public Utility Commission of Texas for their comments on a final draft of this report.

Numerous individuals with the proposed and operating RTOs addressed in this report answered many questions about the operations of their respective RTO. These include Denise Foster of Pennsylvania-New Jersey-Maryland ISO; Mollie Lampi and Kenneth Klapp of the New York ISO; Heather Tindall of the Electric Reliability Council of Texas (ERCOT) ISO; and Mark Volpe of the Midwest ISO. Others helping the author understand to RTO operations include Steve McDonald of PG\&E National Energy Group; Jess Totten of the Public Utility Commission of Texas; Paul Peterson of Synapse Energy; Beth Soholt of the Izaak Walton League; Brent Beerley of Community Energy; Beth Garza of FPL Energy; Denis Bergeron of the Maine Public Utilities Commission; and Paul McCurley and John Simonelli of ISO New England. 


\section{Executive Summary}

Broadly defined, a regional transmission organization (RTO) is an independent organization (profit or non-profit) established for the purpose of operating the transmission assets and providing wholesale transmission services within a defined (usually multi-state) geographic region. Typically, the RTO does not itself own the transmission facilities but instead operates them on behalf of the transmission-owning utilities. An RTO may operate a central energy market in addition to providing transmission services. The functions of RTOs can include facilitating or operating a day-ahead energy market; planning transmission; monitoring markets; managing the queue for generator interconnections; and administering the transmission tariffs for transmission service, congestion pricing and ancillary services.

In recent years, the Federal Energy Regulatory Commission (FERC) has made it a priority to encourage the formation of RTOs. FERC views RTOs as essential features of a competitive bulk power market, as RTOs could: (1) minimize the potential for transmission owners to favor their own generation resources at the expense of other competitors that do not own transmission; (2) minimize transmission rate "pancaking" of power that is transmitted over multiple transmission systems; (3) facilitate the development of market-based approaches for congestion management; and (4) enhance reliability through regional transmission planning and operation.

The path towards RTOs began with two FERC orders. In 1996, the FERC issued Order 888 that required transmission-owning utilities under FERC jurisdiction to provide open access transmission service to eligible wholesale power customers. As part of Order 888, FERC also directed the three centrally-dispatched power pools in the Northeast to open their membership beyond transmission owners to other market participants and to implement open access transmission service. In 1999, the FERC issued Order 2000 that required transmission owning utilities to file their intent with FERC on whether they have or plan to join an RTO, and for RTOs to meet certain criteria to be approved by FERC in order to begin operations as an RTO. More recently, FERC said it would issue a Notice of Proposed Rulemaking in 2002 on certain requirements and services (often termed "standard market design") that must be in all transmission tariffs filed at FERC.

RTOs can be advantageous for renewable energy technologies. RTOs broaden the available geographic market for selling power; potentially remove the heavy impact of additive ("pancaked") transmission charges if power is transmitted over multiple utility transmission systems; and may lead to innovations in power delivery and transmission planning and pricing.

Nevertheless, RTO arrangements and market rules may present new problems and hurdles for renewable energy technologies. Tough financial penalties imposed on generators if they fail to meet scheduled power deliveries may act as a market barrier to intermittent renewable energy technologies. Incompatible transmission arrangements and/or multiple transmission charges between RTOs - so-called "seams" between RTOs-may restrict power markets, and therefore opportunities for renewable energy technologies. 
The bulk of this report focuses on a relatively narrow aspect of RTOs-scheduling of energy and transmission - that is of critical importance to the market viability of intermittent renewable energy technologies. In Order 888, FERC authorized energy imbalance service as one of six ancillary services transmission customers are required to have as part of their transmission service. The energy imbalance service corrects for hourly mismatches between the scheduled delivery and the actual delivery of energy to a load located within a control area. FERC also allowed transmission providers to apply a penalty if energy deliveries vary $1.5 \%$ or more (either higher or lower) from advance energy schedules.

The energy imbalance penalty provisions for under- or over-delivery of energy is designed to keep generators from either chasing price (i.e., over-delivering) or leaning on the grid (i.e., under-delivering), but these provisions may act as an inadvertent market barrier to intermittent renewable energy generators that cannot control their output. The penalty provisions in Order 888 tariffs typically exceed the commercial value of the energy produced by intermittent renewable energy generators. Such penalty provisions make it difficult to obtain project financing, as the risk of incurring energy imbalances is high.

In Order 2000, FERC moved away from the individual utility open-access transmission tariffs required by Order 888 to focus more on creating regional transmission services and tariffs through the creation of RTOs. FERC required RTOs to implement a real-time balancing market to allow transmission customers to balance their energy schedules, and said that having such a market "...will become extremely important as states move to broad-based retail access, and as generation markets move toward non-traditional resources, such as wind and solar energy, that may operate only intermittently." Ideally, the development of a real-time balancing market will result in a deep and liquid market, with multiple buyers and sellers, as contrasted to a penaltybased energy imbalance market that often consists of a single energy imbalance provider that may be the generation affiliate of the transmission owner.

Order 2000 has not yet been fully implemented. Therefore, a key issue for intermittent renewable energy generators is how quickly the transition is from penalty-based scheduling in Order 888-type tariffs to real-time balancing markets that will be part of a fully functioning RTO in Order 2000. Formation of RTOs under Order 2000 is voluntary, and although FERC recently took several important steps to increase participation in RTOs, there are still sectors in the electric power industry, and regions in the country, where RTO participation is relatively meager. Moreover, RTOs are themselves evolving institutions. It may be several years before RTOs are fully functional with robust real-time balancing markets.

More recently, FERC took additional steps related to RTOs and to intermittent renewable energy technologies. FERC announced it will issue a Notice of Proposed Rulemaking on a standard market design that will apply to all RTOs and transmission owners with transmission tariffs filed at FERC. FERC staff has released two white papers on what should be contained in a standard market design, and how transmission rates should be set (FERC 2002b; FERC 2002c). Among what should be included in a standard market design, according to FERC staff, are technology- and fuel-neutral market rules; a requirement that intermittent renewable energy

\footnotetext{
${ }^{1}$ FERC. Regional Transmission Organizations (Order 2000), 89 FERC $\uparrow$ 61,285, slip op., p. 423.
} 
generators can participate in energy, ancillary service, and capacity markets; and a requirement that energy imbalances be settled at the real-time market price.

FERC also issued an order approving the California ISO's provisions on energy imbalances and intermittent renewable energy generators (FERC 2002d). Intermittent renewable energy generators are required to install a California ISO-approved meter and a California ISO data processing gateway to allow for the real-time telemetry of operation and meteorological data. Scheduling coordinators for intermittent renewable energy generators must submit schedules that are consistent with an hourly energy forecast that is developed under supervision of the California ISO and pay a forecasting fee to defray the California ISO's costs of the forecasting service. Positive and negative scheduling deviations from intermittent renewable energy generators will be netted on a monthly basis. Penalties associated with energy imbalances are waived. The California ISO will file a progress report on these provisions with FERC sometime in 2003.

To assess the potential impact of the market rules of RTOs on intermittent renewable energy technologies, we examined how the market rules of four RTOs - the PennsylvaniaMaryland-New Jersey ISO (PJM), the ERCOT ISO, the Midwest ISO and the New York ISO (NYISO) - may affect the development or operation of intermittent renewable energy plants. Since the prevailing market price is usually lower than the average total cost of an intermittent renewable energy generator, it was assumed that the shortfall would be made up through green marketing premiums, revenues from the sale of green certificates or tags, payments or grants from state systems benefits charge programs, state renewables portfolio standards (RPS), or a combination of the above.

In general, the market strategies for renewable energy technologies vary by RTO. For instance, there is only one available strategy for intermittent power generators in ERCOTbilateral arrangements-whereas there are a number of strategies available to intermittent renewable generators participating in the PJM ISO and NYISO. Generally, RTOs with a central energy market have more available market strategies, since options exist for bidding into the central energy market in addition to engaging in bilateral transactions, whereas only various types of bilateral transactions are available in RTOs without a central energy market.

Based on the parameters in this report, intermittent renewable generating plants have the most market success in ERCOT, because of a well-designed RPS, high quality renewable resources, and favorable transmission and scheduling rules. Intermittent renewable generating plants also fare reasonably well in the NYISO, also because of market rules that take into account the non-dispatchability of intermittent renewable resources. Intermittent renewable generating plants do fairly well in PJM, although unlike the NYISO, intermittent renewable generators are ineligible to participate in the installed capability market. In contrast, intermittent renewable resources face much more difficulty scheduling into the Midwest ISO because of penalties for either over-delivering or under-delivering relative to advance energy schedules.

How RTOs are designed and implemented will also have impacts on the market viability of certain renewable energy technologies, and if applicable, the success of state policies such as an RPS or a systems benefits charge. ERCOT's system-wide transmission rate, partial 
exemption from balancing penalties for intermittent renewables, and willingness to build new transmission to interconnect new generating plants, certainly played a major role in $900 \mathrm{MW}$ of new renewables coming on-line in 2001, four years earlier than required to meet the provisions of the Texas RPS under Texas' restructuring law. In the NYISO, exempting intermittent renewables from penalties embedded in the regulation provisions, as well as allowing intermittent renewables to be eligible to participate in installed capacity markets, have resulted in over $100 \mathrm{MW}$ of new and planned wind energy generation in New York.

Because dispatchable renewable energy technologies such as biomass and geothermal do not have the same scheduling issues as intermittent renewable energy generators, a narrower analysis was performed to see whether biomass power can provide ancillary services. Biomass power plants are designed to run at high capacity factors and cannot ramp up and down quickly enough to follow variations in load. Biomass plants can provide operating reserve/non-spinning reserve, but this ancillary service is characterized by a low price and biomass plants will not receive substantial revenues from providing this service. An exception may be landfill methane plants that could potentially provide spinning reserve service, but since landfill methane is generally not stored on site, these plants probably cannot respond quickly enough to load fluctuations to provide spinning reserves.

Seams issues between RTOs can also be a hindrance to not only renewable energy technologies, but other energy resources as well. With Order 2000 now two years old, FERC is moving to expand the size and scope of RTOs in the Northeast, Midwest and Southeast and reduce the problem of seams between RTOs. The Commission tried to accelerate RTO expansion by ordering the three Northeastern ISOs, and three proposed RTOs in the Southeast, to combine, but has slowed down that process after opposition was voiced from state regulators. FERC is now focusing on issuing a standard market design that will apply to all RTOs, and establishing a dialogue with state regulators on expanding the size and configuration of RTOs. 


\section{Overview}

In 1996, after years of industry debate, the Federal Energy Regulatory Commission (FERC) issued Orders 888 and 889 requiring transmission owners under its jurisdiction to provide transmission open access on a non-discriminatory basis for all wholesale transmission customers (FERC 1996; Porter 1996. See text box on next page, "Reserving and Paying for Transmission," to see how transmission service is arranged in various regional transmission organizations (RTOs)). FERC also directed the three tight, centrally-dispatched power pools in the Northeast - the New England Power Pool, the New York Power Pool, and the PennsylvaniaNew Jersey-Maryland Interconnection (PJM) - to open their membership beyond transmission

\section{Figure 1. Proposed and Planned Regional Transmission Organizations}

\section{EEF \\ Regional Transmission Organizations}

Utility Participation as of February 2002

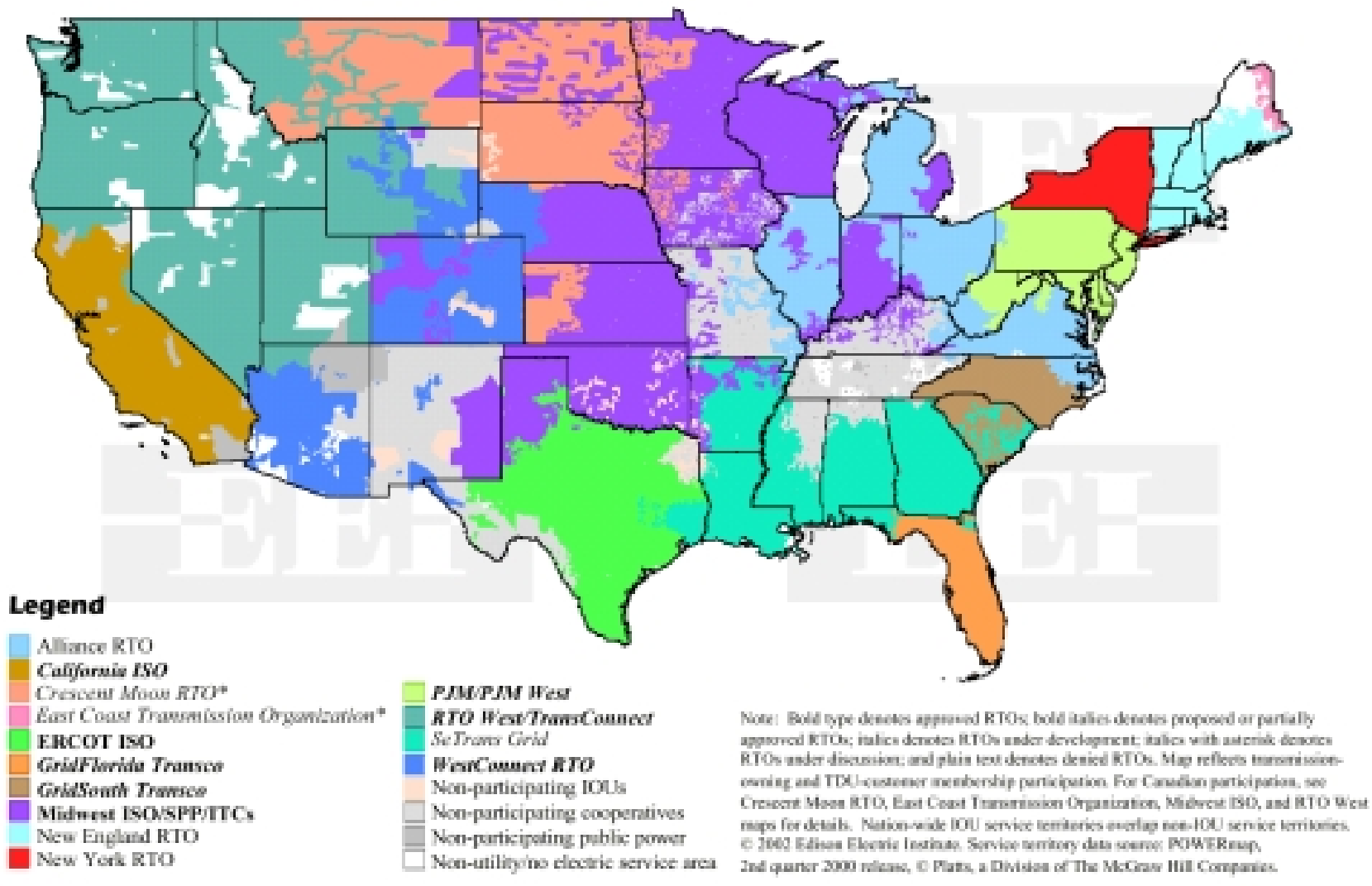

Reprinted with the permission of the Edison Electric Institute: C2002 Edison Electric Institute. Service territory data source: POWERmap, $2^{\text {nd }}$ quarter 2000 release, (C) Platts, a Division of The McGraw Hill Companies. 
owners to other market participants and to implement open access transmission service. California's 1996 electric restructuring law provided additional momentum by requiring the state's three major investor-owned utilities to transfer operation of their transmission assets to an independent administrator.

\section{Reserving and Paying for Transmission}

There are many ways to categorize RTOs, but one important distinction is how the fixed and operating costs of the transmission system (the "embedded costs") in the RTO are collected.

The embedded transmission costs can be allocated to generators or to end-use customers (i.e. load). If transmission costs are allocated to generators, then generators must reserve transmission capacity, as well as submit energy delivery schedules on a day-ahead or hour-ahead basis if there is a centralized energy market as part of the RTO. Some refer to this as a "capacity-based" system. If transmission costs are allocated to load, then it is said that transmission costing is done on a "load pays" basis. Load, rather than generators, reserves a specific allotment of transmission under a load pays arrangement. Scheduling coordinators may act as an intermediary among RTOs and generators and load, as is the case in the ERCOT ISO (termed "qualified scheduling entities" in ERCOT).

If generators must reserve transmission, they can select between point-to-point transmission service (where energy is injected at a certain point and delivered to another point in the transmission system) and network transmission service (where transmission customers can integrate load and resources over a certain area, instead of having to make multiple point-to-point transmission arrangements). Network service is mostly used by transmission-dependent utilities that must meet load, such as rural electric cooperatives and municipal electric utilities. Since most renewable energy generators contribute electric supply and do not meet load requirements, they will most likely not be taking network transmission service.

For point-to-point transmission service, generators can take either firm or non-firm service, with the difference that non-firm service is typically curtailed if there is transmission congestion (in some cases, non-firm transmission customers may continue transmission service if they agree to pay transmission congestion charges in addition to regular transmission charges). Non-firm transmission service is available from one hour to one month, with sequential service terms available. Firm point-topoint transmission service is available for varying terms, typically from one day to as long as in specified agreements with a RTO. If the transmission system is over-subscribed, then requests for long-term firm service will pre-empt existing short-term service, although holders of short-term service can match any request for longer term service. Firm point-to-point transmission customers can modify their delivery and receipt points, but the service at those points is non-firm, and the total of all firm and non-firm service cannot exceed its allotted transmission capacity request.

Transmission pricing for point-to-point service in RTOs is typically done by transmission zones, with each zone equivalent to the service territory of the transmission owner. The transmission rate charged for a specific transaction is set to the transmission zone where the energy is delivered. In the past, FERC has conditioned its approval of ISOs on the filing of a transmission rate for the entire ISOPJM is required to file such a proposal by July 2002 - but because the costs of different transmission systems vary enormously from transmission owner to transmission owner, it likely will be very difficult for all transmission owners in an RTO to reach agreement on an RTO-wide transmission rate.

For the RTOs addressed in this paper, the Midwest ISO uses a capacity-based transmission reservation system, while PJM, the ERCOT ISO and the NYISO pay for transmission on a "load pays" basis. 
After Order 888 was adopted, several ISOs were formed, most predominately the three Northeastern tight power pools and the California ISO. The Electric Reliability Council of Texas (ERCOT) was transformed into an ISO in August 1996. A sixth ISO, the Midwest ISO encompassing the central Midwest, received FERC approval as an RTO in December 2001 (FERC 2001h).

In December 1999, FERC issued Order 2000 requiring transmission owners under its jurisdiction to file either applications to join or form a regional transmission organization, or to explain why it did not join an RTO and explain the barriers to joining or forming an RTO (FERC 2000b). Prospective RTOs must also meet 12 standards set out by FERC - four on characteristics and eight on functions (see the RTO characteristics \& functions text box in Appendix A).

As of May 2002, about 14 RTOs are in various stages of planning or operation. ${ }^{2}$ FERC conditionally approved two RTO proposals (PJM and Midwest ISO) and has refocused its RTO initiative towards authorizing a standard market design that would apply to all RTOs and transmission owners under FERC jurisdiction. FERC plans to unveil a Notice of Proposed Rulemaking on standard market design in summer 2002, and issue a final rule by the end of 2002 or in early 2003.

This report summarizes the development of RTOs and assesses the potential implications for renewable energy technologies. We focus particularly on scheduling provisions, as these have proved problematic in some cases for intermittent renewable energy technologies. We examine how the market rules of four RTOs-the Pennsylvania-Maryland-New Jersey ISO, the ERCOT ISO, the Midwest ISO and the New York ISO (NYISO) - may affect intermittent renewable energy projects such as wind energy generators. We take a more general look at how biomass power may fare in RTOs, specifically whether these technologies can participate in ancillary service markets. We then assess the implications for renewable energy technologies of a Northeast-wide RTO that would combine the three existing Northeast ISOs (the aforementioned PJM and NYISOs, as well as ISO New England). We close with a summary.

\footnotetext{
${ }^{2}$ This includes the Electric Reliability Council of Texas ISO, which is not under FERC jurisdiction.
} 


\section{Intermittent Renewable Energy Technologies and RTOs}

To assess how the operation and design of RTOs may affect intermittent renewables such as wind, solar and run-of-the-river hydro, we examined the operating rules of four RTOs to assess how they may affect intermittent renewables, and consider the various market strategies available to intermittent renewable energy generators to conform to different operating rules. ${ }^{3}$

For intermittent renewables, a critical issue is how schedules submitted in advance (typically day-ahead) are reconciled with actual power deliveries (real-time markets). Order 888 allows transmitting utilities to levy a penalty if actual power deliveries deviate from day-ahead schedules by $1.5 \%$ or more. The purpose of this penalty is to provide an incentive for generators to deliver with precision and to avoid requiring transmitting utilities to go to the wholesale power market on short notice to either make up shortfalls in power deliveries, or to sell over-deliveries. Since intermittent generators cannot control or accurately predict their power deliveries in advance, submitting advance schedules could potentially involve considerable risk. The possible imposition of financial penalties can severely impair market strategies, act as a market barrier, or both. For this reason, we place special emphasis on scheduling rules in RTOs. ${ }^{4}$

Since the prevailing spot market price is typically (but not always) lower than the average total cost of an intermittent renewable energy generator, we assume that the shortfall would be made up through green marketing premiums, revenues from the sale of green certificates or tags, payments or grants from state system benefit charge programs, state renewables portfolio standards, or a combination of the above.

We begin with the PJM ISO, and then turn to the ERCOT ISO, the Midwest ISO, and the New York ISO.

\section{Pennsylvania-New Jersey-Maryland Interconnection ISO (PJM)}

PJM administers the open access transmission tariff, operates the PJM energy markets and capacity credit markets, and oversees the day-to-day operation of the bulk power system of the PJM control area. Entities can bid into the PJM central energy market or engage in bilateral energy transactions with other PJM participants. All generators over 5 MW must be scheduled into PJM's electronic market, otherwise known as "eMarket."

An important element is being a member of PJM. Membership in PJM costs $\$ 5,000$ annually, regardless of company or generator size. PJM membership carries an important benefit in that a generator can sell from and buy into the spot energy market without facing scheduling penalties, such as the energy imbalance penalty found in individual transmitting utility FERC Order 888 transmission tariffs. Appendix B provides more detail on how PJM is designed and operated.

\footnotetext{
${ }^{3}$ The terms "intermittent renewables," "intermittent generators," and "intermittent renewable energy generators" will be used interchangeably throughout the report.

${ }^{4}$ For an assessment of the system impacts of a wind generator in an RTO, see Hirst (2001b).
} 
PJM administers a central energy market in addition to its open access transmission tariff. In June 2000, PJM adopted a two-settlement market consisting of a day-ahead energy market and the real-time energy market. Previously, PJM's central energy market was only one settlement, i.e., a real-time energy market.

In 1999, the PJM central energy market averaged about 30,000 MW per hour. Of this, the spot energy market represented 4,500 MW per hour or $15 \%$; the bilateral market encompassed about 9,000 MW per hour or about 30\%. Net imports were about $500 \mathrm{MW}$ per hour. The rest of the energy supply (about 55\%) was self-supplied by load serving entities (LSEs), primarily by utilities that own generation resources and serve electric load (PJM 2000).

Market participants in PJM's day-ahead market must submit the amount and location of customer load or energy purchases by noon of the day before, for each hour of the next operating day. The buyer can specify the price at which it does not wish to include its load in the energy market rather than pay the day-ahead market price. Similarly, market sellers in the day-ahead market can submit offers to sell energy, regulation, operating reserves or other ancillary services for the next operating day. Energy supply bids to PJM can come from inside or outside PJM, although resources from outside PJM must make their own transmission arrangements to transmit power into PJM. All sellers in the day-ahead market are paid a single price at each hour, i.e., the highest bid price accepted by PJM to serve load at that hour. Bids for providing energy are capped at $\$ 1000$ per $\mathrm{MWh}$, and bids for providing regulation are capped at $\$ 100$ per MWh. Once the PJM posts the initial results of the day-ahead market, a "generation rebidding period" occurs from 4:00 p.m. to 6:00 p.m. in which market participants may change offers for any energy resource that was not selected in the day-ahead market.

PJM was the first to propose and receive FERC approval of locational-based marginal pricing (LBMP). LBMP is designed to reflect the marginal cost of electric generation to meet load, and the cost of delivering that energy through transmission.

If there is no transmission congestion, then the LBMP would be the same at all buses (nodes). With congestion, transmission constraints may keep an inexpensive generator outside the constrained area from serving load within that area during certain hours. When this occurs, a more expensive generator located within the constrained area must be dispatched. While this is essentially the same as redispatch procedures that utilities have always employed, what is different here is that the redispatch costs are charged directly to specific transmission customers, and are incorporated in the price of electricity at the location of the bus. PJM market participants can opt to pay these congestion costs and thereby have their transactions completed, or they may have their transactions curtailed. PJM measures LBMP at approximately 1,600 nodes, with the cost of supplying energy at each node calculated every five minutes. PJM integrates these fiveminute values into an hourly amount for each node.

PJM aggregates the values of some of these nodes into trading hubs to facilitate the creation and offering of standard energy products in the energy marketplace. The energy value reported at each trading hub is the weighted average of the nodes included in that particular trading hub. PJM has three trading hubs: the Western hub (111 nodes); the Eastern hub (237 nodes); and the PJM Interface (three nodes). 
Figure 2. Map of PJM Control Area

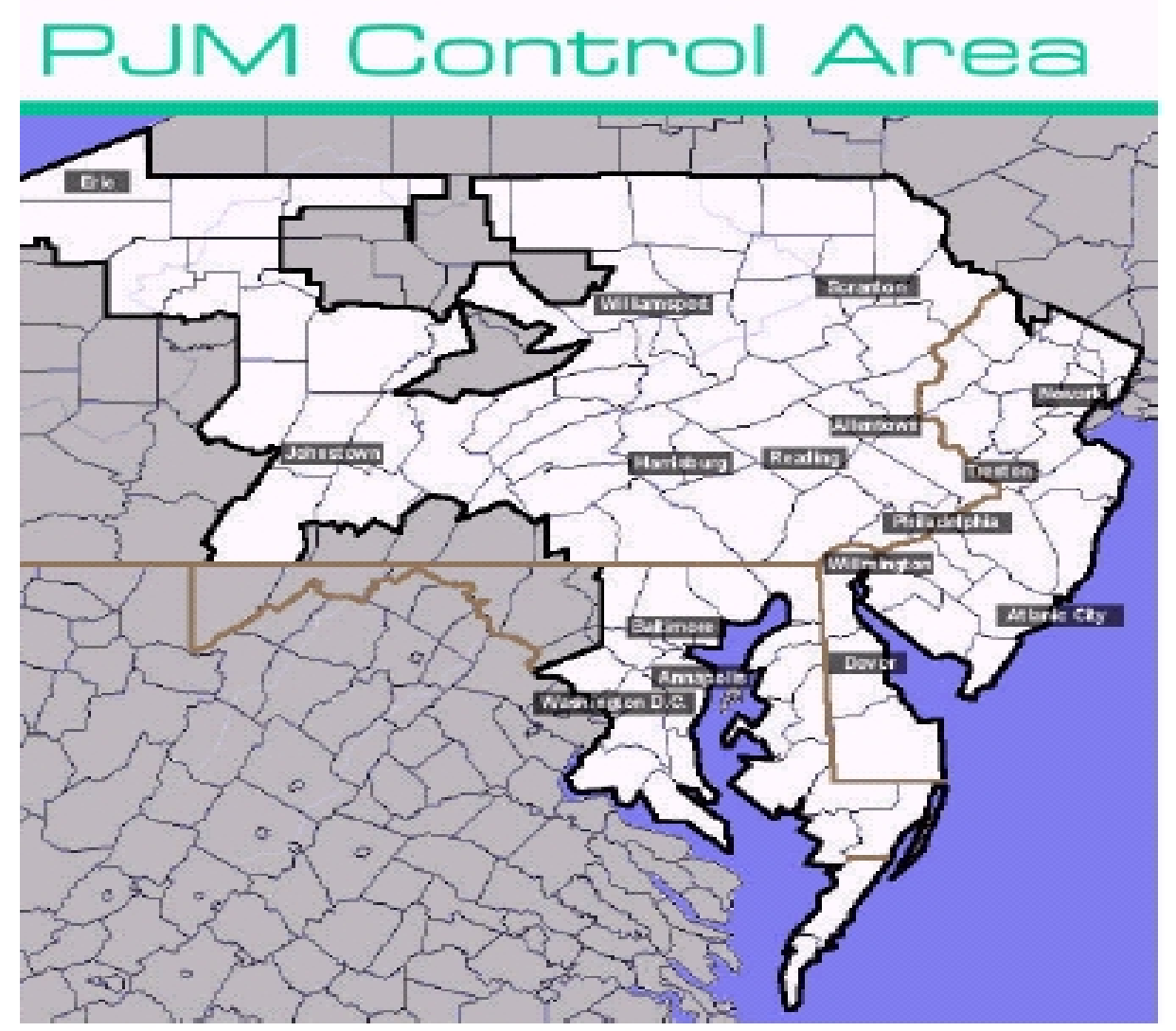

Source: PJM.

PJM also has an installed capacity requirement, also known as "ICAP." Load serving entities (LSEs) must own or purchase capacity resources equal to the load the LSE serves, plus a reserve margin. If the LSE's capacity resources are less than its capacity obligation, then the LSE must pay a minimum penalty of $\$ 177.30$ per MW per day, which is equivalent to PJM's estimate of the installed cost of a combustion turbine. In turn, generators can qualify as a PJM capacity resource and receive revenues by selling part or all of their capacity to an LSE, or through participating in the PJM daily, monthly or multi-monthly capacity credit markets, in addition to whatever revenues they may receive through the PJM energy market or through bilateral contracts. However, intermittent renewable energy generators are not eligible to be an ICAP resource because they do not meet PJM eligibility standards. Because of that ineligibility, intermittent renewable energy generators cannot access an important revenue stream from PJM capacity markets.

Intermittent renewable energy generators have the following alternatives for participating in the PJM ISO: 
- Bid into the PJM market as a price paker (i.e. must-run)

- Bid "unavailable" into the PJM and receive the real-time market price

- Bid into the PJM day-ahead market

- Enter into a bilateral contract in PJM

It should be noted that intermittent renewable energy generators will face a trade-off between balancing energy obligations and operating reserve costs. Intermittent renewable generators that bid advance schedules into the PJM day-ahead market or enter into bilateral contracts in PJM will have to settle any differences between actual energy deliveries and energy schedules at the real-time market price. Intermittent renewable generators that bid unavailable or bid into PJM as a price taker will not have to balance their real-time deliveries with their advance schedules, but will have to pay real-time operating reserve costs if the energy that is delivered exceeds $5 \mathrm{MW}{ }^{5}$ Real-time operating reserve costs generally cost about $\$ 0.50 / \mathrm{MWh}$ over an entire year (Freeman 2002).

In practice, an intermittent generator will have to balance whether the predicted revenues from bidding into the day-ahead market will be high enough (and the confidence is reasonably high for delivering on advance schedules) to offset the risk of incurring costs for balancing overdeliveries and under-deliveries, as well as avoiding the costs of real-time operating reserves. Alternatively, a more conservative strategy may be to bid into PJM as a price taker, or bid unavailable, and pay the relatively predictable costs of real-time operating reserves.

We take each of these scenarios in turn.

Bid into PJM Energy Market as a Price Taker: The intermittent generator can bid as a must-take resource (essentially bidding a zero price) and accept the prevailing real-time market price for all hours and for all output. Under this strategy, the intermittent generator cannot set the prevailing market price in PJM - it can only take the prevailing market price. The intermittent generator will not have to balance its actual energy deliveries with its advance energy schedules, but it will have to pay real-time operating reserve charges.

Bid as "Unavailable" into PJM: Under this option, the intermittent generator notifies PJM that it is unavailable for the day-ahead market or as a price taker, but accepts the daily realtime market price in PJM for any generation. There is no practical difference between bidding unavailable and bidding as a price taker, except constantly bidding zero into PJM may trigger a review by the PJM market monitor. To avoid this, PJM has instructed some of the intermittent renewable energy generators to bid unavailable into PJM (Freeman 2002). As with the price taker option, the intermittent generator cannot set the prevailing market price in PJM-it can only take the prevailing market price. The intermittent generator will not have to balance their actual energy deliveries with their advance energy schedules (since there was no advance schedule), but it will have to pay real-time operating reserve charges.

\footnotetext{
${ }^{5}$ If generation exceeds $5 \mathrm{MW}$ (e.g., $6 \mathrm{MW}$ ), then the costs of real-time operating reserve is computed on actual delivery $(6 \mathrm{MW})$, not the difference between actual delivery and the $5 \mathrm{MW}$ threshold. However, if generation is less than $5 \mathrm{MW}$ (e.g., $4 \mathrm{MW}$ ), then no charge is assessed for real-time operating reserves.
} 
This is how at least two recent Pennsylvania wind projects - the 15 MW Mill Run wind project in Fayette County and the 9 MW Somerset wind project in Somerset County-are participating in PJM. The wind plants are designated as unavailable and output from the two wind projects is sold into the PJM real-time energy market, while "green tags" representing the environmental attributes of wind energy are sold to customers (Freeman 2002). Wind energy currently is a very small percentage of available resources in PJM, but it is likely that PJM will want wind energy generators to use a different market strategy than being unavailable if a significant amount of wind becomes operational in PJM.

While PJM allows suppliers to bid as price takers or to be unavailable and receive the real-time price, it also wants predicted schedules a day in advance, and for potential schedule changes to be reported hourly. Therefore, an intermittent renewable energy generator would tell PJM that it expects to generate a certain number of MW per hour in a day, but any change from that schedule requires PJM to be notified at least 20 minutes before the next operating hour. Since intermittent renewable energy generators, by definition, experience varying output, the PJM notification requirements essentially dictate that operators be in continuous contact with PJM, which may be burdensome for both the generator and PJM. Reportedly, PJM is in consultation with some intermittent renewable energy generators about how to ease the burdens associated with the PJM scheduling provisions (Freeman 2001).

Bid into PJM Day-Ahead Market: The intermittent generator can bid a firm volume and price into the day-ahead market, and settle any under-deliveries or over-deliveries at the realtime market price. If the intermittent generator sells more energy than is scheduled, then it would be paid the real-time market-clearing price for that energy. The converse is true if the intermittent generator delivers less energy than it scheduled-the intermittent generator would pay the real-time market-clearing price for that energy. The intermittent generator will take on some measure of risk with this option, depending on how many megawatts it bids into the dayahead market and whether it over-delivered or under-delivered on its day-ahead schedule. The intermittent generator will have to balance this risk with how precisely it can schedule (using tools such as wind forecasting, for wind generators) versus higher revenues from potentially higher day-ahead market prices (if load is expected to be high, for instance).

Bilateral Contract in PJM: Here, an intermittent renewable energy generator would enter directly into a bilateral contract with another party, either for the green tags or for the green tags and the generation. For just the green tags, a typical transaction would be to sell the green tags to another entity, and to sell the energy into either PJM day-ahead or real-time energy market. Alternatively, the intermittent generator can sell the renewable energy generation to a third party at a certain price (e.g., the PJM Western Hub price) and the green tags at a separate price. In either event, the intermittent renewable energy generator will also have to settle any under-deliveries or over-deliveries into PJM at the real-time market price.

\section{Electric Reliability Council of Texas (ERCOT) ISO}

The ERCOT ISO operates wholly in the state of Texas and is not subject to FERC jurisdiction. ERCOT encompasses about 200,000 square miles, or $75 \%$ of Texas. There are 
about 18 million customers in the ERCOT system, and collectively, they account for $85 \%$ of the load in Texas.

The ERCOT ISO is operated and priced as a single integrated system, effectively making all transmission service network service. Load in Texas pays for all transmission and ancillary services, except for energy imbalances. Transmission pricing is based on a system-wide rate that includes losses and a scheduling fee to ERCOT. The ERCOT ISO also charges transmission service providers administrative fees.

Figure 3. The Operations of the ERCOT Bilateral Market

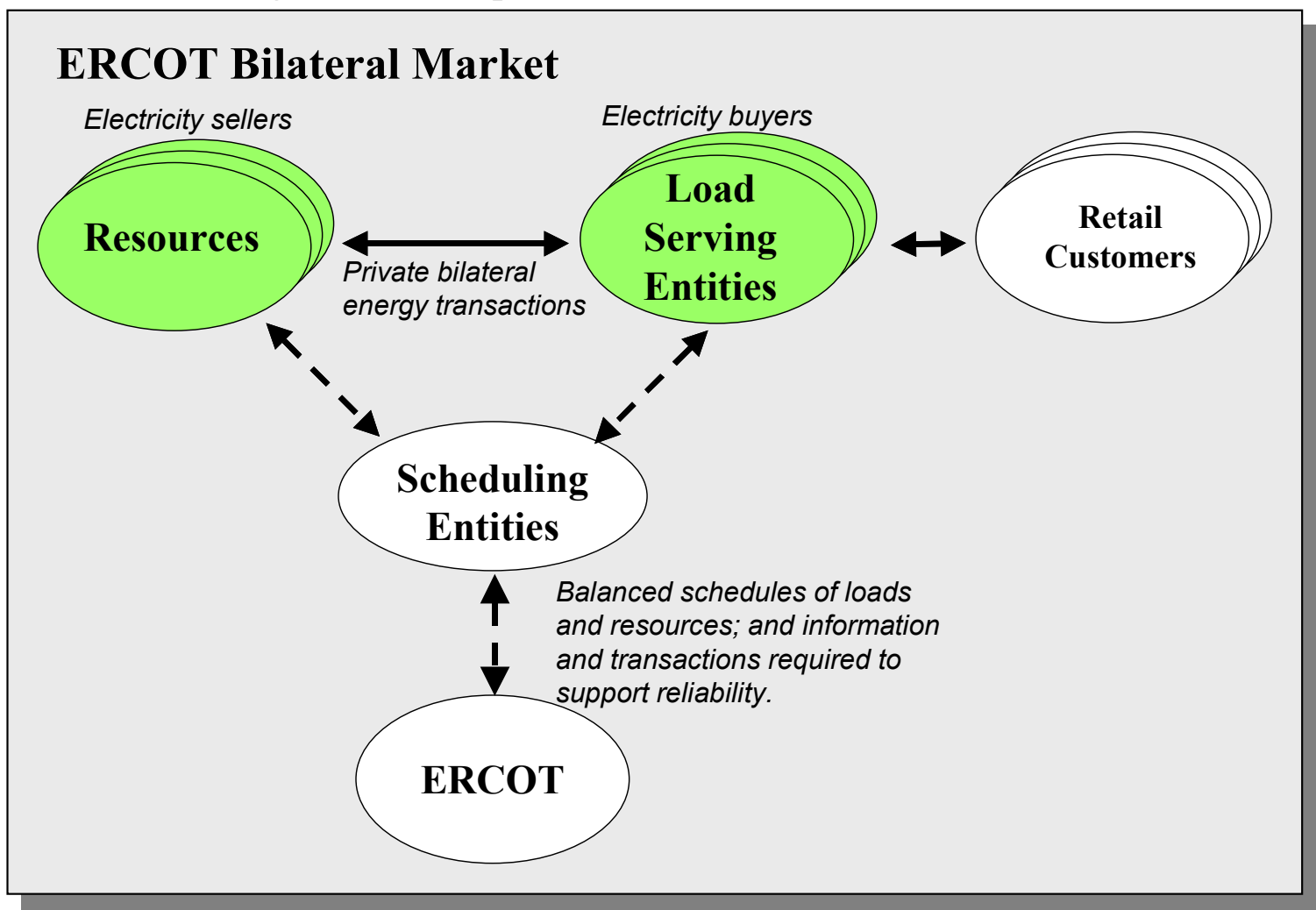

Source: ERCOT: The Market Guide. Taylor, Texas: ERCOT, February 22, 2001, p. 10. 
Transmission can also be extended to hook up new generation plants, with the costs being borne by all users of the system, rather than directly assigned to the new generators. ERCOT calls this "driveway access" for interconnecting new generators. This has made it easier to develop wind projects in western Texas, where the wind resources are especially good, and to build transmission in order to serve load that is predominately in central and eastern Texas (NWCC 2000).

In terms of scheduling, ERCOT's approach relies on bilateral contracts between generators and LSEs. LSEs, in turn, communicate via scheduling coordinators, or qualified scheduling entities (QSEs), as they are called in ERCOT. QSEs are responsible for providing all wholesale energy to serve their load, as ERCOT does not operate an energy market, and for communicating their schedules to ERCOT. ERCOT does operate an ancillary services market for QSEs that choose not to self-provide ancillary services, and a balancing energy market to balance advance schedules and actual deliveries.

Effectively, there is only one wholesale supply option in ERCOT, and that is entering into bilateral contracts with power marketers, LSEs or with a QSE. Transmission congestion pricing is an emerging development in ERCOT, as discussed further in Appendix B. ERCOT created four congestion zones-North, South, West and Houston. To resolve congestion, ERCOT will procure either replacement energy in advance, or balancing energy near real-time, to alleviate the transmission constraints. The highest accepted bid for replacement energy or balancing energy determines the zonal market clearing price for that congestion zone. Since February 15, 2002, those congestion costs are directly assigned to entities that cause it by scheduling across congestion zones. QSEs can hedge against congestion by purchasing transmission congestion rights (TCRs) that entitle the holder to schedule $1 \mathrm{MW}$ of power at any time over a transmission constraint between zones. ERCOT auctions TCRs, with $60 \%$ of available TCRs auctioned yearly and the remaining $40 \%$ auctioned monthly.

Intermittent renewables are exempt from scheduling penalties as long as total metered intermittent renewable generation does not exceed $150 \%$ or fall below $50 \%$ of the intermittent renewable resource's schedule in any schedule interval. If there are deviations beyond the $50 \% / 150 \%$ provision, then QSEs either pay or are paid the zonal market clearing price (ERCOT $2001 \mathrm{~b}$ ). Therefore, the $50 \% / 150 \%$ provision for intermittent renewable generator removes a significant risk for QSEs of having to pay market prices for not meeting schedules, for being paid a fraction of market prices for over-delivering compared to schedules, and/or having to pay a separate charge for multiple schedule deviations.

Renewable energy resources, particularly wind, are quite strong in Texas. Only North Dakota has a better wind resource in the United States than Texas, according to the American Wind Energy Association (AWEA 2001), using data from the National Renewable Energy Laboratory (NREL 2001). With the combination of a strong RPS and transparent transmission rules, renewable energy resources in Texas in 2001 are being priced from $\$ 32$ to $\$ 47$ per MWh (Sloan 2001). As a result, almost $900 \mathrm{MW}$ of renewable energy capacity came on-line in Texas 
in 2000 - most of it wind and almost all of which is located in a three-county area near Fort Stockton in West Texas. ${ }^{6}$

\section{Midwest Independent System Operator (Midwest ISO)}

The Midwest ISO presently includes 25 transmission owners and covers an area from North and South Dakota to western Ohio. Overall, the Midwest ISO encompass parts or all of 14 states and parts of three different reliability councils - the East Central Reliability Coordination Agreement (ECAR); the Mid-American Power Pool (MAPP) and the Mid-American Interconnected Network (MAIN). As presently configured, the Midwest ISO would include over 74,000 miles of transmission lines, and serve a peak load of 81,000 MW (MW ISOe 2001). The Midwest ISO recently became the second RTO to be approved by FERC and began operating in February 2002 (FERC 2001h).

The Midwest ISO is a non-stock, not-for-profit corporation with functional control over all network transmission facilities above $100 \mathrm{kV}$ and all network transformers where the two highest voltages exceed $100 \mathrm{kV}$. The Midwestern ISO does not operate as a single control area. Transmission owners that are currently control area operators would continue to operate their control area for local generation control and economic dispatch. However, transmission owners would follow the instructions of the Midwest ISO for redispatching generation, curtailing load, and providing reactive supply, voltage control or other ancillary services.

The Midwest ISO is a reservations-based RTO where transmission customers must reserve a specified amount of transmission service-network, firm or non-firm point-to-point transmission service. Zonal transmission pricing will be used for a transition period of six years after the Midwest ISO begins operations, with transmission pricing set to the control area of each transmission owner in the Midwest ISO.

An important element for intermittent renewable energy generators are the Midwest ISO's provisions regarding energy imbalances and inadvertent energy exchanges that would apply to control area operators and transmission service customers. Staying in balance would require parties to use bilateral contracts, either in advance or within the hour; to make secondary short-term (within the hour) transmission and/or scheduling arrangements; or to use a market posting system (arranged by the Midwest ISO) where buyers and sellers can conduct short-term energy and/or transmission transactions.

\footnotetext{
${ }^{6}$ However, transmission availability and constraints may be a problem in getting renewable energy out of western Texas to serve load in central Texas. Transmission owners in ERCOT are constructing two new east-to-west 345 $\mathrm{kV}$ transmission lines to allow wind energy (and natural gas generation) from West Texas to deliver to load in Dallas, San Antonio, Austin and Houston. However, at least for now, thermal operating limits restrict exports out of west Texas to between 300 and $800 \mathrm{MW}$, meaning wind energy may be curtailed from time to time over the next two years (Wiese 2001).
} 


\section{Figure 4. The Midwest ISO's Service Territory}

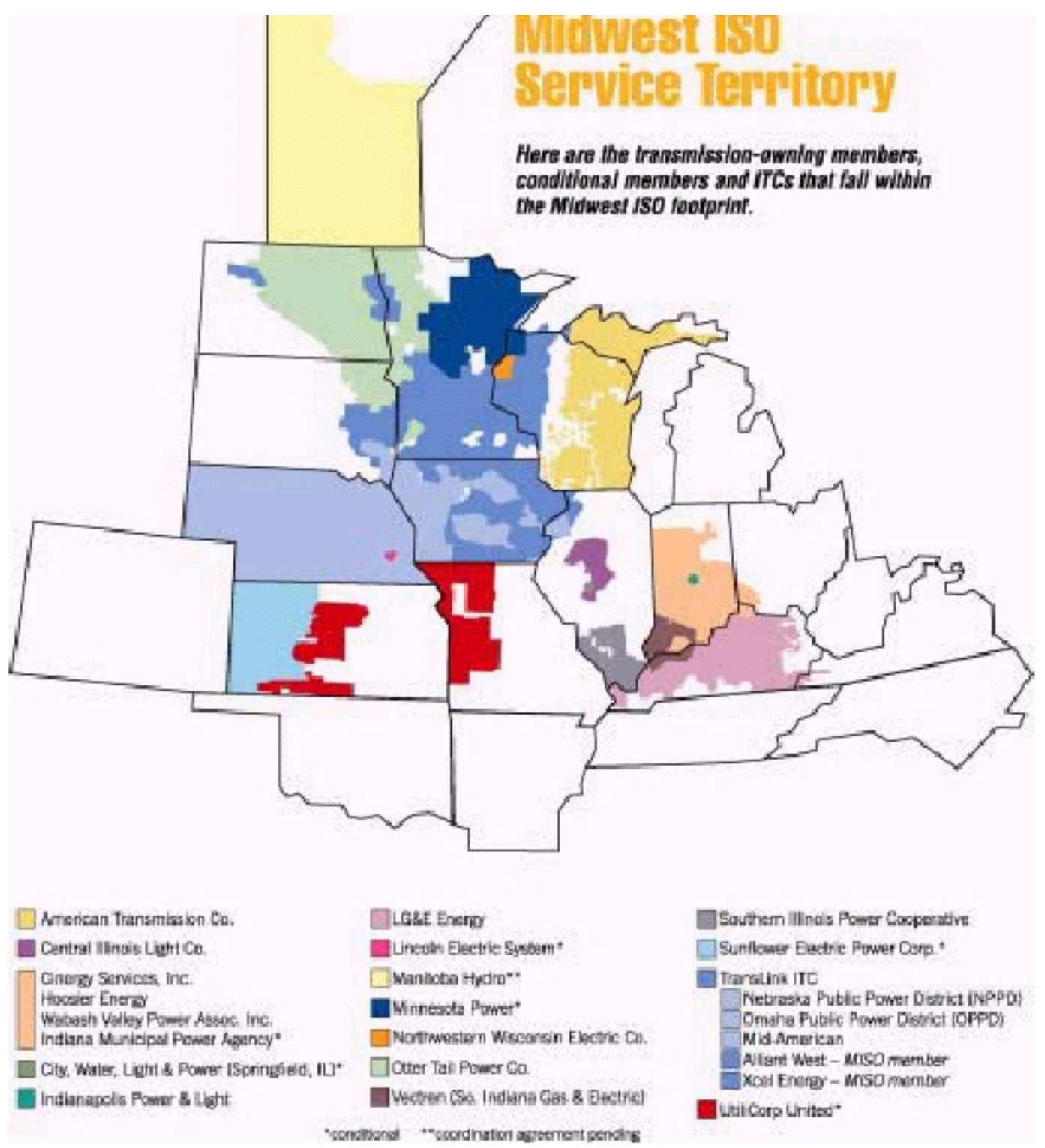

Source: Midwest ISO

The Midwest ISO's long-term goal is to establish a privately-created central energy market that is designed for congestion management and for real-time balancing transactions. If a central energy market is not in place, then hourly market prices will be determined for each control area. The hourly price can be established in different ways. If the control area operator is making hourly energy purchases or sales, then the hourly market price would be the megawattweighted average price of energy during that hour. If the control area operator is not making hourly energy purchases or sales, then the peak and off-peak hourly market price would be the 
megawatt-weighted average of all peak and off-peak purchases and sales made in the control area.

The Midwest ISO also would impose penalties if either generators or loads do not stay within their advance schedules. Deadbands specify an allowable deviation, with smaller entities permitted a larger percentage deviation, as measured by the entity's total load or generation. For example, a $100 \mathrm{MW}$ entity would have a deadband of $7 \mathrm{MW}$ (7\%), while a 10,000 MW entity would have a deadband of $74 \mathrm{MW}(0.74 \%)$. The specific proposed penalties are as follows:

- For over-delivery, generators or transmission customers would receive $85 \%$ of the hourly marginal price. For under-delivery, generators or transmission customers would pay the transmission provider $115 \%$ of the hourly marginal price.

- For over-delivery or under-delivery of $25 \%$ or more for $10 \%$ or more of the hours in a month, then transmission customers or generators would receive $75 \%$ of the hourly marginal price for over-delivery, and pay $125 \%$ of the hourly marginal price (MW ISOb).

Because of these penalty provisions, intermittent renewable energy generators will find it nearly impossible to schedule into the Midwest ISO. In some cases, the value of the penalties nearly exceeds the value of the energy output from the intermittent renewable energy generator. As noted later, these issues may diminish if the Midwest ISO successfully launches its hybrid congestion and real-time balancing proposal, or if a central energy market is created that does not incorporate scheduling penalties.

For now, since there is not a central energy market within the Midwest ISO, intermittent renewable energy generators must sell power via bilateral transactions. There are three possible transactions for the renewable generator in the Midwest ISO:

- Schedule non-firm transmission with the Midwest ISO, sell power to another entity, and be subject to the Midwest ISO's scheduling penalties.

- Schedule a smaller amount than the installed capacity of the intermittent renewable energy generator to avoid scheduling penalties.

- Sell the intermittent renewable energy to a load serving entity and essentially transfer the energy imbalance risk to that load serving entity.

To get a sense of the impact of the energy imbalance penalties, we did some rough calculations for $10 \mathrm{MW}$ wind energy generator using the market scenarios described above. For the market price, we calculated the average price for 2000 at $\$ 26.05 / \mathrm{MWh}$ for the Cinergy spot market, using data from Megawatt Daily (Megawatt Daily 2001). ${ }^{7}$ We estimated wind energy

\footnotetext{
${ }^{7}$ The average peak price for 2000 at the Cinergy hub was 3.643 cents/kWh, while the average off-peak price was $1.568 \mathrm{cents} / \mathrm{kWh}$. We derived these estimates by averaging the monthly peak and off-peak prices at the Cinergy hub and computing the simple average of on- and off-peak prices.
} 
generation costs at $\$ 45 / \mathrm{MWh}$, based on projects installed in 1999 and $2000{ }^{8}$ For transmission rates, we also averaged the Midwest ISO's on-peak and off-peak drive-through non-firm transmission service, with a result of $\$ 3.05 / \mathrm{MWh}$. However, transmission rates in the Midwest ISO vary considerably by zone; consequently, our scenario is illustrative but not necessarily representative. We also applied the $\$ 1,000$ annual Midwest ISO membership fee, and Midwest ISO fees for scheduling and administration (MW ISOd). The Midwest ISO also applies a fee to regional through and out serve to recover revenues lost from the elimination of transmission pancaking, and we included that rate in the scenarios (FERC 2002a). The results are detailed in Table 1, as well as in Appendix C.

\section{Table 1}

\section{Scenario Results for Intermittent Renewable Energy Generator in Midwest ISO}

\begin{tabular}{|c|c|c|c|c|c|}
\hline Strategies & $\begin{array}{l}\text { Expected } \\
\text { Annual } \\
\text { Output of } \\
\text { Intermittent } \\
\text { Generator } \\
\text { (MWh) }\end{array}$ & $\begin{array}{l}\text { Expected } \\
\text { Energy } \\
\text { Price } \\
(\$ / M W h)\end{array}$ & $\begin{array}{c}\text { Expected } \\
\text { Annual } \\
\text { Intermittent } \\
\text { Generator's } \\
\text { Revenue } \\
\text { Requirements* }\end{array}$ & $\begin{array}{l}\text { Expected } \\
\text { Net } \\
\text { Revenue }\end{array}$ & $\begin{array}{l}\text { Additional } \\
\text { Revenue } \\
\text { Needed to } \\
\text { Recover } \\
\text { Expected } \\
\text { Costs }\end{array}$ \\
\hline $\begin{array}{l}\text { Non-Firm } \\
\text { Bilateral } \\
\text { Transaction }\end{array}$ & 25,492 & $\$ 26.05$ & $\$ 1,147,122$ & $\$ 24,282$ & $(\$ 1,171,404)$ \\
\hline $\begin{array}{l}\text { Schedule smaller } \\
\text { amount ( } 1 / 3 \text { of } \\
\text { capacity) }\end{array}$ & 8,412 & $\$ 26.05$ & $\$ 1,147,122$ & $\$ 173,932$ & $\$(973,190)$ \\
\hline $\begin{array}{l}\text { Schedule smaller } \\
\text { amount ( } 1 / 2 \text { of } \\
\text { capacity) }\end{array}$ & 12,745 & $\$ 26.05$ & $\$ 1,147,122$ & $\$ 264,049$ & $\$(883,073)$ \\
\hline $\begin{array}{l}\text { Sell to marketer } \\
\text { or LSE for } \\
\text { "blended } \\
\text { product" }\end{array}$ & 25,492 & $\$ 26.05$ & $\$ 1,147,122$ & $\$ 529,098$ & $\$(618,024)$ \\
\hline
\end{tabular}

* The expected annual revenue requirements for the intermittent generator is derived by multiplying expected generation by the expected $\$ / M W h$ cost of the intermittent generator.

At the outset, we should note that the Midwest ISO recently suspended its energy imbalance provisions (MW ISOf). When the Midwest ISO began operating, it followed the energy imbalance provisions in each transmission owner's open access transmission tariff that was filed at FERC in compliance with Order 888. These energy imbalance provisions can nearly

\footnotetext{
${ }^{8}$ A number of wind energy generating plants became operational in the Midwest in 2001, but we were unable to access any cost-of-energy information.

${ }^{9}$ Drive-through transmission service is when power is transmitted from one end of an RTO and through and out the RTO to a transmission customer outside the RTO. The on-peak transmission rate for drive-through non-firm transmission service is $\$ 4.13$ per MWh, and $\$ 1.96$ per MWh for off-peak transmission service.
} 
be as punitive as for energy over-deliveries and under-deliveries as the Midwest ISO's original energy imbalance provisions. ${ }^{10}$ The Midwest ISO will continue with the energy imbalance provisions in each transmission owner's open access transmission tariff until the Midwest ISO adopts its congestion and real-time balancing market, described more in Appendix B.

Bilateral Non-firm Transaction: We first assume that all $10 \mathrm{MW}$ of a wind energy plant is scheduled for sale to a bilateral customer, and the full amount is scheduled for non-firm transmission. We assume that there would be under-delivery or over-delivery of $25 \%$ or more for $10 \%$ of the hours in a month. We further assume that one-third of the output would be delivered on schedule and receive the full spot market payment; one-third would be underscheduled and be charged 125 percent of the spot market payment; and one-third would be overscheduled and receive 75 percent of the spot market payment.

The result is the intermittent generator would receive only about $\$ 24,000$ of net revenues per year after receiving lower payments because of over-scheduled deliveries and paying for under-scheduled deliveries. That is far short of the $\$ 1.64$ million in annual revenues we estimate this project would need for viability. In essence, the penalties virtually exhaust the value of the energy.

Bilateral Transaction at Reduced Capacity: Another option is for the intermittent generator to schedule the smallest amount of capacity that a generator can confidently schedule without incurring energy imbalance charges because of under-delivery. We assumed first that only one-third of the $10 \mathrm{MW}$ of rated capacity would be scheduled, and then did a separate simulation for one half of the rated capacity. In both cases, we did not apply any energy imbalance charges due to either under-scheduling or over-scheduling. Essentially derating the intermittent generator resulted in a predictable revenue decline, with the intermittent renewable energy generator receiving about $\$ 174,000$ in revenues for selling one-third of the rated capacity, and about $\$ 264,000$ in revenues for selling one half of the rated capacity. While energy imbalance provisions are avoided or minimized, the lost revenue from foregone sales could be relatively large.

Bilateral Transaction with Load Serving Entity: Generation from the intermittent generator could be sold to a load serving entity, such as a vertically integrated utility, that essentially transfers the risk of incurring energy imbalance charges to the purchaser. In this case, intermittent generators would receive about $\$ 529,000$ net revenues. An alternative is to sell the energy to a load serving entity, but to sell the green tags in a separate transaction.

In essence, the intermittent generator cannot directly schedule with the Midwest ISO without exposure to the significant risk of energy imbalance charges for under-delivery, and/or lower revenues from lost energy sales. A separate proposal was made to exempt intermittent generators from imbalance penalties, contingent upon the Midwest ISO's acceptance of a petition showing that the generator cannot control its output; can arrange dynamic scheduling

\footnotetext{
${ }^{10}$ For instance, the energy imbalance provisions calls for transmission customers to pay the one Midwest utility $110 \%$ of the hourly energy price the utility incurs if the transmission customer delivers less energy than scheduled, and for the utility to pay the transmission customer $90 \%$ of the hourly energy price if the transmission customer delivers more energy than is scheduled.
} 
with a local control area operator; and can buy available transmission capacity in forward or spot markets to reflect transmission reservations (Wiese 2000b). This proposal was abandoned for lack of support.

These issues may diminish if the Midwest ISO incorporates its hybrid proposal for congestion and real-time balancing, or if a central energy market is created that includes these features (see Appendix B for details.) Intermittent generators would then be able to minimize the risk of imbalance penalties through short-term energy purchase and sale transactions. The Midwest ISO tentatively plans to incorporate the hybrid proposal by 2003 (MW ISOe). However, FERC directed the Midwest ISO to incorporate whatever materializes out of FERC's efforts to develop a standard market design for all RTOs to follow (FERC 2001h). In addition, MISO recently announced plans to work with PJM and the Southwest Power Pool on a single market design, and that may also impact the Midwest ISO's timing for the hybrid proposal.

\section{New York Independent System Operator (NYISO)}

The NYISO consists of the transmission assets of eight transmission owners located in New York and a small part of New Jersey. It includes 11,775 miles of transmission and about 35,000 MW of generating capacity. Like PJM, the NYISO consists of an integrated open access transmission system and a central energy market. The NYISO administers the open access transmission tariff; operates central energy market and capacity markets; and oversees the dayto-day operation of the bulk power system of the NYISO control area.

The NYISO has favorable provisions for intermittent renewable generators. $^{11}$ Intermittent generators are eligible for revenues from capacity markets, are exempt from regulation penalties up to $500 \mathrm{MW}$, and can bid in the day-ahead and real-time markets with relative ease. In addition, New York has a relatively robust SBC program that has helped fund the development of several renewable energy projects in New York (Bolinger et al. 2001).

Transmission service is provided when the NYISO accepts day-ahead schedules that are submitted by generators and loads. Non-firm service is provided as part of hour-ahead or realtime schedules, although such transmission service would be curtailed if there were transmission congestion. Transmission service charges (TSCs) are assessed to loads receiving transmission service within the NYISO. A NYISO participant that initiates a bilateral transaction has to pay a TSC and any transmission congestion charges, if transmission congestion exists. Similar to PJM ISO, the NYISO uses locational-based marginal pricing (LBMP) for congestion pricing. Transmission pricing is done by zone, with 11 zones in the NYISO. The transmission rate for either network or point-to-point service is based on the zone where the energy is delivered.

\footnotetext{
${ }^{11}$ Unless otherwise noted, the source for this section is Letendre and Wooley (undated).
} 
Figure 5. The New York ISO's Zones

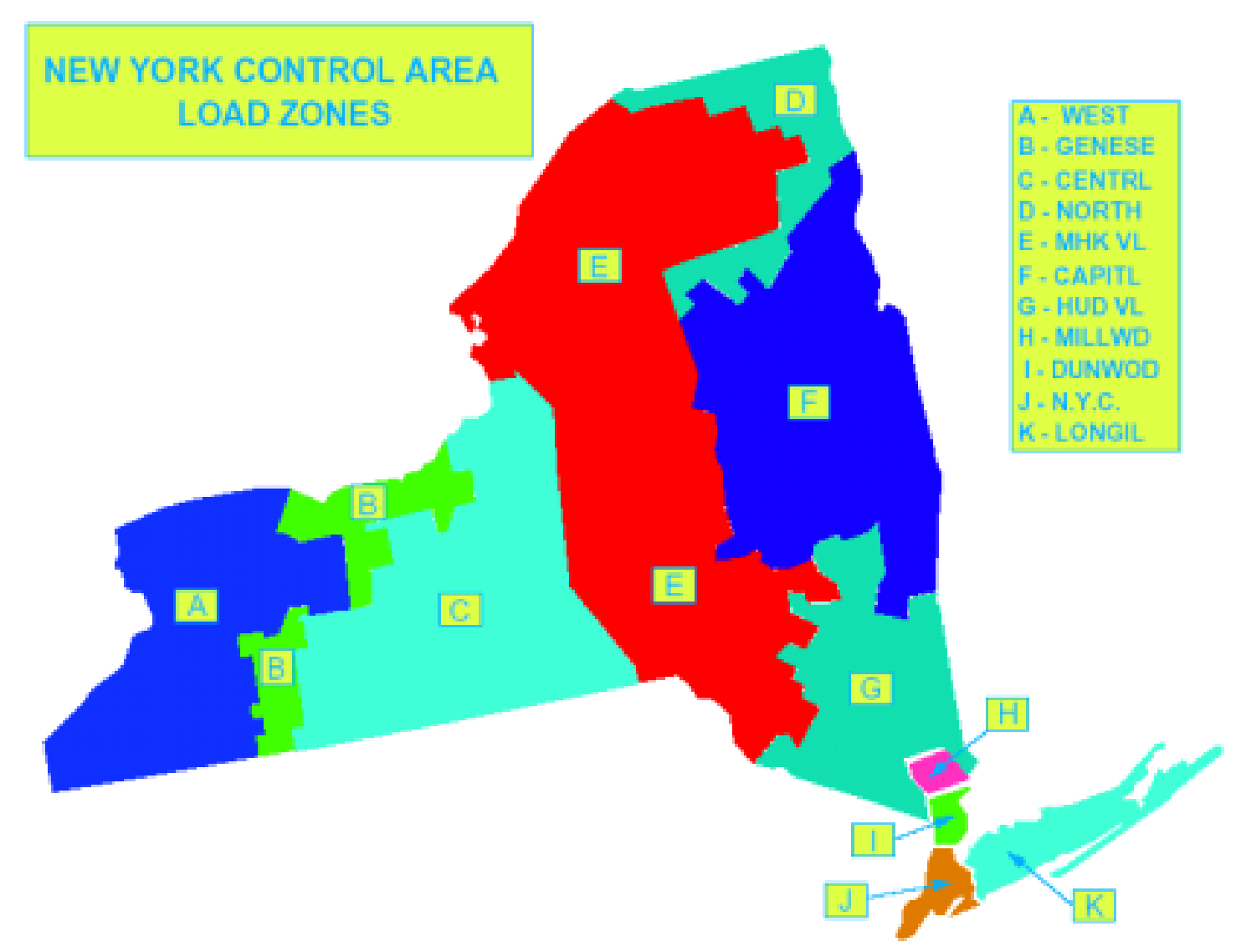

Source: New York ISO.

Like PJM, the NYISO requires load-serving entities to have sufficient installed capacity to meet their peak electric loads, plus a capacity reserve that is determined by the New York Reliability Council (NYRC). Intermittent renewables are eligible to be classified as installed capacity resources in the NYISO. ${ }^{12}$ The NYISO relies on an unforced capacity methodology (UCAP) for determining capacity pricing. Under UCAP, a probability factor is applied to a generator installed capacity, based on the generating facility's operating data from the most recent 12 months (NYISO 2001a). UCAP does not affect intermittent renewable energy generators, since the NYISO already discounts the eligible rating of intermittent generators based on their capacity factor (Lampi 2001b).

Payments for UCAP are determined through the results of three auctions administered by the NYISO: a six month "strip" auction for the summer and winter; a monthly auction; and a deficiency auction for LSEs that do not have enough UCAP resources to meet their load requirements plus the capacity reserve margin. The UCAP prices vary considerably, from zero

\footnotetext{
${ }^{12}$ Intermittent renewable energy generators are also eligible for installed capability payments in ISO New England (ISO New England 2000b).
} 
(when no capacity is needed or when markets do not clear) to $\$ 12 / \mathrm{kW}$ for the six-month auction periods.

Embedded in embedded the NYISO's regulation provisions are penalties for underscheduling or overscheduling. The NYISO exempts existing intermittent renewable energy generators and up to $500 \mathrm{MW}$ more of new intermittent renewables that begin operating after November 1999 from these penalties (NYISO 2001b). ${ }^{13}$

We believe there are five market strategies for an intermittent renewable energy generator in the NYISO:

- Bid directly into the NYISO day-ahead market.

- Bid directly into the NYISO hour-ahead market.

- Sell the energy output from the intermittent renewable energy facility to another entity through a bilateral transaction.

- Transmit the energy output from the intermittent renewable energy facility outside of the NYISO to states in New England with a renewable portfolio standard.

- Sell the energy output from the intermittent renewable energy facility directly to a load serving entity in New York as a "load modifier."

Bid Directly into the NYISO Day-ahead Market: The wind energy generator could bid into the day-ahead market, and if the bid is accepted, would be paid the market-clearing price for the scheduled power. Any difference in actual power deliveries from the day-ahead bid would be settled at the real-time price. For over-deliveries, the wind energy generator would be paid the real-time price multiplied by the MW the wind generator delivered over schedule. For underdeliveries, the wind generator would pay the real-time price times the megawatts not delivered. An intermittent renewables generator will have to balance whether the potential revenues from bidding into the day-ahead market will be high enough to offset the risk of incurring costs for balancing over-deliveries and under-deliveries.

Bid Directly into the NYISO Hour-ahead Market: A wind energy generator that does not want to be exposed to potential balancing charges can bid into the hour-ahead market. This market is advisory in the NYISO and is meant for load or generators to adjust their day-ahead bids before settlement. If the wind generator's bid is deemed economic, then it will be scheduled and the generator paid the real-time market price. The NYISO also resets the wind schedule to actual metered delivery before real-time settlement. It should noted, however, that there will certainly be differences in the day-ahead and real-time market prices. For instance, in the NYISO, the monthly average day-ahead price was higher than the monthly average real-time price for six out of the 12 months in 2001 (NYISO 2001g). Intermittent generators will have to

\footnotetext{
${ }^{13}$ Also exempt are up to $365 \mathrm{MW}$ of topping or extraction turbine generators that supply steam to New York City's district steam system and operating QF facilities.
} 
decide whether the risk of incurring potential balancing charges in the day-ahead market is worthwhile in order to garner the potentially higher day-ahead market price.

Sell the intermittent energy output in a bilateral transaction to another entity: Here, transmission service charges would apply and are paid by either the generator or the power purchaser, depending on who initiated the transaction. The TSC charge will be set based on the zonal transmission rate in the transmission zone that the energy is delivered to. ${ }^{14}$ The intermittent renewable energy generator is still eligible for UCAP payments. ${ }^{15}$ The regulation exemption also still applies. The balancing energy obligation is the responsibility of whoever initially scheduled the bilateral transaction.

Bilateral transaction into New England: In this scenario, the intermittent renewable energy generator can sell into the market created by the RPS policies in Connecticut, Massachusetts or Maine. ${ }^{16}$ The final Massachusetts RPS regulations require a contract for transmission delivery into ISO New England for renewable energy projects located outside of ISO New England (MA DOER 2001). We will focus on that requirement in this scenario. The Connecticut and Maine RPS regulations also require physical delivery into ISO New England but do not require a specific transmission transaction. ${ }^{17}$

The transaction would require a bilateral transaction into ISO New England. In turn, this would require paying a "wheeling out" fee from the New York ISO. In New York, the wheeling out fee is based on the zone where power exits the NYISO, and that would either be the zone associated with Central Hudson Gas \& Electric, or the Niagara Mohawk Power Corp. zone (NYISO 1999). The intermittent renewable energy generator would also not be eligible for UCAP payments in New York since power is being transmitted out of New York and into New England.

To transmit the power into New England from New York and qualify for the Massachusetts RPS, the intermittent renewable energy generator must procure an external unit energy 1 (for energy only) or energy 2 (for energy and capacity) contract from ISO New England (NEPOOL 1999). No transmission charge is levied as long as ISO New England's regional

\footnotetext{
${ }^{14}$ The NYISO has a TSC calculator on its web site where one can calculate TSC charges for specific transactions if one knows the source (the origination point) and the sink (the destination point). The calculator is available at http://www4.nyiso.com/markets/graphs/tsccalc.html.

${ }^{15}$ Only energy limited "special case resources" (defined subsequently) and intermittent renewable energy generators can receive UCAP payments and not be required to bid into the day-ahead market. Other generators must bid into the day-ahead market in order to receive UCAP payments.

${ }^{16}$ As a draft of this paper was being finalized, the NYISO and ISO New England announced a plan to explore creation of a single market design covering both ISOs, and forming the Northeast Regional Transmission Organization. Among other things, ISOs plan to address market standardization; governance; transmission tariffs; transmission planning; environmental protection; consideration of ITCs; and coordination with neighboring control areas. Negotiations are proceeding in earnest, and both ISOs hope to file a market design with FERC by July 2002 (ISO New England 2002).

${ }^{17}$ Connecticut requires that an out-of-region renewable energy generator have a contract with a supplier selling energy to Connecticut customers to qualify for the Connecticut RPS (Quinlan 2001). Maine requires that the out-ofregion renewable energy generator have a sale or contract path into ISO New England, along with some demonstration that the renewable energy generation has not been sold more than once or used to satisfy an RPS requirement in another state (Tannenbaum 2001).
} 
networked transmission system is used. That service accounts for about $65 \%$ of ISO New England's system, but if local transmission service (non-PTF service) is used, then a transmission charge is levied based on the zone where the generation is delivered. ${ }^{18}$ ISO New England states that most transmission transactions involve both the regional network transmission system and the local transmission system (NEPOOL).

Since the power is being transmitted into New England, the market price that the wind energy generator faces would be the market price in ISO New England, rather than the market price in a zone in the NYISO. Although ISO New England does have a capacity market for generators, and intermittent generators are eligible, the intermittent renewable generator in New York may not be eligible using an external unit 1 energy contract, and external unit 2 energy contracts have scheduling requirements that intermittent renewable generators would not be able to meet.

External unit energy 1 or energy 2 contracts in ISO New England require specific generating units to be nominated for delivery of energy and for hourly schedules to be submitted to ISO New England. Any deviations from those schedules are put in an "inadvertent exchange" account that is settled monthly between control areas, i.e., ISO New England and the New York ISO (NEPOOL 1999). The unit-specific and hourly scheduling requirements do not work well with intermittent renewable energy generators. While no financial penalties are involved, control area operators strongly prefer that resources not contribute to their inadvertent exchange accounts (Simonelli 2001). ISO New England says it eventually plans to re-examine its tariffs for incorporating intermittent renewable energy resources in New York (McCurley 2001).

In sum, it could be somewhat more difficult for out-of-region renewable energy generators to competitively sell renewable energy and qualify for a state RPS in another state. We should note, however, that the New Jersey RPS accepts renewable energy generators that sell power into the New York ISO as eligible for the New Jersey RPS, as long as the other eligibility criteria are met (NJ BPU 2001). That would most closely comport with the first scenario we discussed. Therefore, it is likely that if renewable energy generators sought to respond to a state RPS, they probably would select the New Jersey RPS before any of the RPS programs in the New England states.

Sell Energy to an LSE as a "Load Modifier." Under this scenario, a renewable energy generator would sell its output to an LSE, typically an electric distribution utility, as "negative load." The load serving entity would include the renewable generation as part of its scheduling into the NYISO. In other words, the LSE would "net out" the renewable energy generation from the load schedules it would submit to the NYISO. NYSEG's Schedule 10, for example, pays the renewable energy generator the regional locational-based marginal price, minus any incurred charges from the NYISO. Because the NYISO exempts intermittent renewable energy generators from regulation and underscheduling penalties, these incurred charges would likely be modest. The generator would have to pay metering charges to the electric utility. The generator may also receive UCAP payments if power deliveries are during peak demand hours, but these must be negotiated with the utility (NYSEG 2000).

\footnotetext{
${ }^{18}$ Non-PTF service is transmission service over transmission lines not operated by ISO New England.
} 
Like the other scenarios, the intermittent renewable energy generator may receive UCAP payments but under the category of "special case resources." The NYISO defines these resources as "... distributed generators of $100 \mathrm{~kW}$ or higher that are not visible ..." to the NYISO market scheduling system (NYISO 2001f). Special case resources must be able to operate for a minimum of four consecutive hours each day, unless subject to operating limitations as determined by environmental permits, and then the limit is two hours. Special case resources are also exempt from bidding requirements to qualify for UCAP. To ensure that there is not double counting of UCAP, either the LSE or the generator must notify the NYISO of who receives the UCAP credit - either the generator or the LSE. Also, the UCAP of special case resources can only be claimed in increments of $100 \mathrm{~kW}$ - a $590 \mathrm{~kW}$ project, for example, would be rounded down to $500 \mathrm{~kW}$. Special case resources can be aggregated into a single block to minimize the effect of this requirement (NYISO 2001e).

If the intermittent renewable energy generator receives the UCAP credit, then this would be similar to bidding into the NYISO energy market, or selling energy in a bilateral transaction (with the buyer paying TSC charges). If the LSE receives the UCAP credit, then the economics worsen for the intermittent renewable energy generator, absent compensation by the LSE for the UCAP credit.

This scenario may work for intermittent generators, although with a number of caveats. UCAP arrangements, as well as perhaps separate capacity arrangements, must be made with the LSE. LSEs may prefer special case resources that are likely to run at a time that the peak is likely to occur, thereby reducing their capacity procurement obligation (in MW) for the following year. A reduced impact on peak translates to a MW for MW lower capacity requirement and also lowers the reserves that must be purchased. Under these arrangements and assuming that the solar resource coincides with the LSE's peak demand, wind may not do as well as solar, since solar resources are likely to have a greater impact on reducing peak demand requirements. 


\section{Biomass Power and Ancillary Services}

In this section, we look at how biomass power generators may provide ancillary services. We define biomass power to include wood residues, waste-to-energy, and landfill methane.

Biomass power is different among renewable energy technologies in that biomass is a combustion technology, and is not dependent on resource availability such as wind or sun. Therefore, biomass power projects will not face the scheduling issues that have been the theme of this paper thus far.

In this vein, wood residue and waste-to-energy biomass projects are similar to baseload fossil projects such as coal-fired plants in that they are high-capacity-factor, dispatchable generating plants. Landfill methane projects are also dispatchable and typically have high capacity factors, although they are much smaller in capacity than wood residue or waste-toenergy biomass plants, and they use reciprocating or gas turbines.

Wood residue and waste-to-energy plants do share one characteristic with intermittent renewable energy projects: their generating costs typically are higher than the average spot market price. Consequently, these projects likely will have to access additional revenue streams to cover their costs. The alternative revenue streams could include the state RPS policies, state SBC programs, and the green marketing premiums that were discussed earlier in the context of intermittent renewable energy technologies. However, we should note that biomass power may face more stringent eligibility standards for state RPS policies than intermittent renewable energy technologies, and may even be excluded in some cases (Porter 2000). Other alternative revenue streams potentially available to biomass power include capacity markets (if the RTO has such a market), and tipping fees for waste-to-energy plants. State tax incentives for agricultural (if applicable) and wood residue projects, while not revenue enhancers, do serve to increase residual revenues net of costs.

Much of the currently operating biomass power capacity sells power to local electric utilities through long-term contracts signed in the 1980s under terms of the Public Utilities Regulatory Policies Act (PURPA). These contracts are beginning to revert to less economically attractive terms and conditions (such as lower energy prices based on spot market prices or natural gas prices), or are (or will be shortly) expiring altogether. A handful of operating biomass power projects have negotiated buy-outs of their power purchase contracts with electric utilities. These projects are either bidding into RTO capacity and energy markets or selling their output under fixed price contracts to intermediate parties such as power marketers, who in turn are bidding into RTO capacity and energy markets.

With a central energy market as in the NYISO and PJM ISO, the biomass generator has one of two choices. It can bid as a must-run generator into the spot market and take the prevailing spot market price. The biomass generator cannot set the spot market price under a must-run arrangement. Alternatively, the biomass power generator can submit hourly schedules and prices into the day-ahead market. If the generator is selected, then it will be paid the dayahead price, and it can also set the day-ahead market price if it is the marginal unit. 
If a capacity market exists in an RTO, then biomass power generators can participate in those markets as well. The capacity markets can be especially important to biomass power generators as they may help provide at least some of the additional revenues necessary to make up the difference between the revenues from spot market energy prices and the capital cost of the biomass generating plant.

\section{Biomass Power and Ancillary Service Markets}

Transmission customers that purchase transmission service from either a transmitting utility or an RTO must have sufficient ancillary services to support their transmission service. These ancillary services may be self-provided by the transmission customer, may be purchased through bilateral arrangements, or may be purchased from the RTO. FERC requires the RTO to be a provider of last resort for ancillary services.

Ancillary service markets vary by RTO, ranging from relying on the RTO to provide ancillary services in combination with bilateral markets (Midwest ISO) to a use of a centralized daily auction for ancillary services (the NYISO). Because biomass power is dispatchable and can submit advance schedules, we examined whether ancillary service markets could provide an additional revenue stream to biomass power generators.

Under Order 888, FERC requires six ancillary services to be provided. The ones we are concerned with are the following:

- Regulation and frequency response, which is a service to follow the moment-tomoment variation in generation and load to maintain frequency at 60 cycles per second.

- Operating reserve/spinning reserve, which is additional generation to serve load in case of an unplanned event such as the outage of a major generation facility. Spinning reserve is generation that is on-line and operating at less than maximum output and is ready to serve additional load very quickly (within 10 minutes).

- Operating reserve/non-spinning reserve, which is supplemental generation, also to serve load in case of an unplanned event such as an outage of a major generation facility. Non-spinning reserve, however, is not on-line, but must be able to respond within 30 to 60 minutes.

The other three ancillary services are: (1) scheduling, system control and dispatch; (2) reactive power; and (3) energy imbalance (when there are schedule deviations between advance energy schedules and actual energy deliveries). The transmission provider must supply the first two ancillary services, while energy imbalance can be procured from the transmission provider or from other market participants.

Focusing first on wood residues and waste-to-energy biomass projects, we start by assessing the possibility of providing regulation and frequency response. Both wood residue and waste-to-energy projects require ramp up time, and do not quickly ramp up and down in response 
to changing electric system requirements. These facilities are designed to run "flat out" and are not designed to follow load, i.e., vary output quickly (Siegrist 2001). Regulation and frequency response requires generators to either provide more energy or less energy on very short notice (on a minute-to-minute basis). Because wood residue and waste-to-energy biomass projects cannot respond quickly to control area requests for increases or decreases in energy supply, they are not well equipped to provide regulation and frequency response service.

For similar reasons, wood residue and waste-to-energy biomass projects are also not well positioned to provide spinning reserve service, since both technologies cannot ramp up to full capacity within 10 to 15 minutes (Freeman 2001). This leaves operating reserve/non-spinning reserve service. Typically, control area operators solicit this kind of service if they believe electric demand for that day will be higher than predicted by load serving entities, or if enough generation has not bid into an RTO energy market to meet load (Hirst 2001a). Generally, operating reserve/non-spinning reserve service is considered a lower value ancillary service, since control area operators can rely on spinning reserves if supplies of that service are adequate. The lower value of operating reserve/non-spinning reserve is reflected in the lower price this ancillary service receives in the market. Prices for this type of reserve service in the NYISO in 2001, for instance, were typically at \$2/MWh and below (NYISO 2002). Therefore, while wood residue and waste energy generators could provide this kind of service, the economics may not be worthwhile for them to do so.

Landfill methane projects do not have this limitation. Using reciprocating engines or gas turbines, these projects can respond more quickly to directions from control area operators. Conceivably, landfill methane projects could provide spinning or non-spinning reserves, and perhaps regulation service. Few landfill methane projects, however, have any way to store the gas that is produced by the landfill in case more landfill gas is produced than is needed for ancillary service markets. Landfill methane is generally combusted as it is produced. Therefore, landfill methane projects, at least in their current configurations, are not well suited for supplying ancillary services.

Based on the foregoing, biomass power, other than landfill methane, can only provide operating reserve/non-spinning reserve service. Because that type of ancillary service is not highly valued in the electric market, revenues for biomass power generators for providing this service are likely to be scant. Landfill methane can perhaps provide other types of ancillary services such as spinning reserves, but because landfill methane projects generally do not store landfill gas on-site, then most landfill methane projects probably are not able to supply ancillary services as well. 


\section{Creating a Northeast-Wide RTO: \\ A Further Look at "Seams" Issues}

In July 2001, FERC issued a number of rulings on regional transmission organizations. The Commission largely affirmed PJM's RTO filing as being in compliance with Order 2000, but ruled that the filings by the NYISO and ISO New England did not meet the requirements of Order 2000. Furthermore, FERC ordered that all three ISOs enter into accelerated mediation to craft a Northeast-wide RTO largely based on the PJM "platform" incorporating the "best practices" of the other two RTOs (FERC 2001d). In September 2001, the FERC administrative law judge issued his report to FERC (FERC 2001e), which included a business plan for the development and implementation of the Northeast RTO.

Basic features of the three ISOs appear in Table 2 below.

Table 2

The Three Northeastern Independent System Operators

\begin{tabular}{|c|c|c|c|c|}
\hline ISOs & $\begin{array}{c}\text { First Year } \\
\text { of Operation }\end{array}$ & $\begin{array}{l}\text { States } \\
\text { Included }\end{array}$ & Transmission & $\begin{array}{c}\text { Generating } \\
\text { Capability }\end{array}$ \\
\hline $\begin{array}{c}\text { Pennsylvania- } \\
\text { New Jersey- } \\
\text { Maryland ISO }\end{array}$ & 1998 & $\begin{array}{l}\text { Most of } \\
\text { Pennsylvania, } \\
\text { New Jersey, } \\
\text { Maryland, } \\
\text { Delaware, } \\
\text { D.C., Virginia }\end{array}$ & 13,000 miles & $66,000 \mathrm{MW}$ \\
\hline $\begin{array}{l}\text { ISO New } \\
\text { England }\end{array}$ & May 1999 & $\begin{array}{l}\text { Connecticut, } \\
\text { Maine, } \\
\text { Massachusetts, } \\
\text { New } \\
\text { Hampshire, } \\
\text { Rhode Island, } \\
\text { Vermont }\end{array}$ & 8,000 miles & $26,750 \mathrm{MW}$ \\
\hline New York ISO & $\begin{array}{c}\text { December } \\
1999\end{array}$ & $\begin{array}{l}\text { New York and } \\
\text { parts of New } \\
\text { Jersey }\end{array}$ & 11,775 miles & $\begin{array}{c}\text { About } \\
35,000 \mathrm{MW}\end{array}$ \\
\hline
\end{tabular}

This section reviews the options for a Northeast RTO that stakeholders have put forward, and the implications for renewable energy technologies. It should be noted that subsequent developments have changed the composition and timing of a Northeast RTO. In November 2001, FERC issued an order slowing the process of organizing the Northeast RTO and describing more on how FERC will address RTO market design. In the order, FERC states that it intends to proceed in the RTO effort in two ways: to resolve RTO geographic scope and 
governance issues, and to resolve transmission tariff and market design issues for public utilities and RTOs. Also, FERC states that its goal in standardizing market rules is to balance the need to eliminate discrimination and excessive costs in transmission services with the need to permit regional differences and market innovations. To achieve this goal, FERC plans to issue a notice of proposed rulemaking for a standard electricity market design in Summer 2002, and finalize the rule by the end of 2002 (FERC 2001j). In a separate order, FERC announced plans to form an RTO panel made up of both state and federal interests to act as a forum for "constructive dialogue" on RTO development between FERC and state commissions (FERC 2001k).

Subsequently, in January 2002, PJM entered into a letter of intent with the Midwest ISO and the Southwest Power Pool (SPP) to work towards a common energy market. PJM characterized the agreement as more than a collaborative agreement but less than a merger (PJM 2002a). Concurrently, PJM released preliminary results from a study it commissioned on the potential costs and benefits to PJM of a Northeast RTO. Press reports indicated that generator revenues in PJM would increase by $\$ 188$ million, potentially resulting in higher power costs to consumers. As a result, PJM reportedly is considering withdrawing from efforts to form a Northeast RTO in favor of pursuing its arrangement with the Midwest ISO and SPP (Megawatt Daily 2002a). Furthermore, both the NYISO and ISO New England have announced plans to negotiate a single market design common to both ISOs. Both ISOs hope to file the market design plan with FERC by July 2002 (ISO New England 2002).

\section{Options for a Northeastern RTO}

Stakeholders participating in the Northeast RTO mediation reached consensus that a technology assessment for creating a Northeast RTO, if initiated in November 2001, could be finished by spring 2002. There also was general consensus that a regional transmission planning process can be developed by the end of 2002, and a regional transmission tariff can be in place by the middle of 2003. The major difference among the three options discussed below is the time required to complete the design and implementation of a single regional energy market based on PJM, as potentially modified by "best practices" identified in the NYISO and ISO New England. Three different timetables have been proposed and are discussed further below. ${ }^{19}$ It should be noted that each of these timetables assumes that the integration and merger process (per direction from the FERC) began by November 2001, which did not occur.

The first option, which is backed by the NYISO and ISO New England, would have a single Northeastern RTO market design in place by the end of 2004. That date may be extended if new complexities or new design requirements are introduced. A transition board of directors would be created, and that board would devise (or manage) an implementation plan. The NYISO and ISO New England state that creating a single market in the Northeast is a large and

\footnotetext{
${ }^{19}$ Perhaps the most contentious issue at the moment involving a single Northeast RTO involves the governance structure. Because this report is more focused on scheduling and tariff issues, governance issues are discussed only briefly. The NYISO and ISO New England proposal would create a board of equal representation from all three ISOs; the Integrated Northeast Market Concept would include stakeholders with its board of directors; and the PJM Regional Networked Market Concept would assign five board seats to PJM, three to the NYISO, two to ISO New England, and one to the chief executive officer of the Northeast RTO.
} 
complex task, and significant time and resources would be necessary to ensure success. They also assert that their approach ensures the meaningful adoption of "best practices," and that failing to allow for adoption of best practices could mean significant new costs for ratepayers in New York and New England.

The second option, sometimes termed the "Integrated Northeast Market Concept," would make certain market design elements operational by the end of 2002, and achieve a single Northeastern energy market near the end of 2004. An independent board, with stakeholder input, would evaluate proposed best practices and technology before incorporating these into the Northeast RTO. This option is supported by the New York transmission owners.

The third option, supported by PJM and numerous other parties, is based on extending the PJM platform across the entire Northeast but retaining the existing local control centers and energy management systems in all three ISOs to address local reliability issues and to act as data servers to the regional market. PJM refers to its proposal as the "Regional Networked Market Concept." PJM believes that systems implementation and market trials would take about two years, but implementation efforts could begin immediately. The single energy market could be achieved as early as the end of 2003. PJM also believes that most of the best practices identified by the NYISO and ISO New England can be incorporated without delaying any proposed market starting dates, if adopted in the post-mediation process that would take place in the first three months after FERC issues an order directing adoption of this plan. The basic thrust of this proposal is to implement a single Northeastern market expeditiously while still addressing critical reliability concerns.

\section{Implications for Renewable Energy Technologies}

Given the early stages of developing a Northeast RTO, it is difficult to fully evaluate the advantages and disadvantages such a RTO could mean for renewable energy technologies. Too many details are unresolved, and FERC has not yet made the important decisions about which business model it prefers. The following should be viewed as a preliminary assessment.

How beneficial the Northeast RTO could be for renewable energy technologies depends on which of the three proposals are adopted, the speed with which they are fully adopted, and whether any of the best practices identified by the NYISO and ISO New England are incorporated or not. It essentially boils down to a trade-off between how quickly a regional RTO and a single regional energy market can be adopted versus full incorporation of best practices across the entire Northeast RTO.

Specific to intermittent renewable energy technologies is the NYISO's specified best practices of exempting intermittent renewables from regulation penalties and allowing renewables to be eligible for installed capacity credits, as well as ISO New England's generation tracking system that allows for the sale, purchase, or trading of non-energy attributes separate from the energy commodities. We should note that there is not universal stakeholder support for adopting the identified best practices without review, either by FERC, by a board, or by a 
stakeholders group. Therefore, it cannot be assumed that the best practices in NYISO that work well for renewable energy would be adopted.

There is reason to believe that the PJM proposal may prevail as the market design for the Northeast RTO, if a Northeast RTO moves forward. The FERC order setting up mediation to create a Northeast RTO specifies that PJM be used as a "platform." In addition, a majority of stakeholders that participated in the Northeast RTO mediation favored PJM's proposed Regional Networked Market Concept.

Certain aspects of the PJM platform are favorable for renewable energy technologies. PJM is free of the scheduling and energy imbalance provisions that are featured in other proposed and operating RTOs around the country. However, as noted in the PJM section of this report, intermittent renewables cannot qualify as installed capacity resources in PJM as they can in ISO New England and the NYISO.

PJM asserts that its Regional Networked Market Concept proposal could achieve a single regional energy market more quickly than the other proposals. However, it does so in part by overlaying a regional RTO structure, and using PJM, NYISO, ISO New England, and PJM West as the four control areas that provide basic control area functions such as energy dispatch and balancing. PJM has indicated that almost all of the best practices can be adopted but only in the local control areas. Under this proposal, the best practices, such as exemption from regulation penalties for intermittent generators, could continue but be limited to the NYISO control area, just as it is now. In some cases, this may not be too much of a concern, if energy transactions are within a control area or if PJM adopts some of the recommendations of renewable energy companies. However, in some cases, conflicts may arise. For instance, both the State of New York and ISO New England have different and conflicting energy tracking systems, and PJM is working on developing its own energy tracking system that, depending on the outcome, may also be different enough to conflict with the other two.

The proposal from the NYISO and ISO New England has the virtue of incorporating best practices across the entire Northeast RTO, thereby minimizing some of the conflicts just discussed. However, implementation of this proposal would require more time to achieve a single regional energy market, as late as 2004, and with a disclaimer that it could be even later than 2004 if new complexities arise. The costs of extending these best practices across the entire region also may be higher than limiting them to a regional control area and creating a regional RTO structure, as advocated by PJM.

\section{Implications of "Seams" Between RTOs}

As RTOs are planned or begin operating, an important issue arises as to whether different RTO designs and operating practices act to "wall off" individual RTOs, and make it difficult or impractical for cross-RTO-border wholesale power transactions to take place. Differences in RTO design or operating practices are popularly termed "seams" issues, referring to the boundaries between RTOs. 
Although simple in concept and in definition, seams between RTOs can encompass innumerable items, ranging from the highly detailed to completely different scheduling and pricing practices. Some examples of seams issues between RTOs include:

- Transmission Reservation and Scheduling: Whether generators and marketers must schedule and pay for transmission and ancillary services, or whether these services are paid for by load.

- Settlement Markets: How real-time markets are settled, and in particular, whether energy imbalances are settled in real-time markets or whether a penalty is imposed, either financially or through taking of generation, or through both.

- Transmission Congestion Management: Whether transmission congestion is managed physically (through curtailments and/or redispatch) or financially (through congestion pricing).

- Transmission Rights Allocation: Whether rights to transmission are allocated to hedge against transmission congestion, and whether transmission rights are allocated on a physical basis (actual acquisition) or on a financial basis (through payments to transmission rights holders).

- Scheduling of Load and Generation: Deadlines for submitting day-ahead load and generation schedules differ by RTO; different RTOs have different rules regarding whether amended schedules can be submitted; RTOs differ in the availability of hourahead schedules.

- Installed Capacity Requirements: RTOs may or may not have capacity reserve requirements for ensuring reliability. More specifically, capacity reserve requirements also differ, from whether it is ICAP or UCAP, and whether capacity rights can be traded or purchased through an auction.

- Multiple RTO Fees: A transaction that encompasses more than one RTO may be assessed transmission and access charges by each RTO, depending on the specific RTO. The multiple charges are reminiscent of the multiple charges assessed by transmission providers if transactions crossed more than one transmission system, which was an impetus for the formation of RTOs in the first place.

- Ancillary Services: What specific ancillary services are required by each RTO, and whether these ancillary services can be procured through a competitive auction or must either be self-provided or purchased from the RTO.

\section{Conclusion}

Renewable energy generators face a trade-off between speed in creating a regional energy market, and in fully integrating all three Northeast ISOs into a single RTO. Furthermore, it is 
unclear whether the best practices that renewable energy stakeholders favor, such as qualifying for ICAP in ISO New England and in the NYISO, and having a tradable certificate system as in ISO New England, will apply across the entire Northeast RTO. Finally, it also appears that FERC itself may slow down the process to create a Northeast RTO in order to more fully involve state regulators in the Northeast and to work on a standard market design applicable to all RTOs. 


\section{Summary}

This report examines a relatively narrow function of RTOs-energy and transmission scheduling - that is of critical importance to the market viability of intermittent renewable transmission energy technologies. Scheduling penalty provisions for under-delivery or overdelivery of energy that is designed to keep generators from either chasing price or leaning on the grid may act as an inadvertent market barrier to intermittent renewable energy generators that cannot control their output. RTOs that rely on these penalty provisions first embodied in Order 888 make it difficult for intermittent generators to schedule, with the cost of the penalties incurred as a result of schedule deviation expected to exceed the value of the energy produced by intermittent renewable generators. Until a full transition is made to robust and liquid real-time balancing markets as required under Order 2000, intermittent generators will have to rely on exemptions from penalties such as the exemptions in ERCOT or the NYISO.

A number of market strategies for intermittent renewable energy technologies for participating in RTOs are profiled in this report. These market strategies vary by RTO depending upon RTO rules and regulations. Generally, RTOs with a central energy market have more available market strategies, since options exist for bidding into a central energy market as well as engaging in bilateral transactions, whereas only bilateral transactions are available in RTOs without a central energy market.

This report also notes that in most instances, intermittent renewable energy generators must rely on funding mechanisms to augment revenues obtained through energy market transmissions, including funding from system benefit charge funds, revenues from the sale of green tags to green power customers, revenues from the sale of renewable energy credits (or renewable energy itself) under state renewable portfolio standard policies, and/or "green" power premiums over market price that may be available in certain segments of the market. Indeed, the success of these state policies may depend in part on how RTOs are designed and implemented.

This paper also looked at whether biomass power can provide ancillary services or not. Biomass power plants are designed to run flat out and cannot ramp up and down quickly enough to follow variations in load. Biomass plants can provide operating reserve/non-spinning reserve, but this ancillary service is a low-priced ancillary service and biomass plants will not receive large revenues from providing this service. An exception may be landfill methane plants that could potentially provide spinning reserve service, but since landfill methane is generally not stored on site, these plants probably cannot respond quickly enough to provide spinning reserves.

Seams issues between RTOs can also be a hindrance to not only renewable energy technologies, but other energy resources as well. With Order 2000 now two years old, FERC is moving to expand the size and scope of RTOs in the Northeast, Midwest and Southeast, as well as prodding RTOs to work on reducing seams between RTOs through collaborative and reciprocity arrangements. FERC tried to accelerate RTO expansion by ordering the three Northeastern ISOs, and the three proposed RTOs in the Southeast, to combine into a Northeast RTO and Southeast RTO, respectively, but has slowed down that process after opposition was voiced from state regulators. FERC is now focusing on issuing a standard market design rule that will apply to all RTOs and establishing a dialogue with state regulators on expanding the 
size and configuration of RTOs. Congress is also showing increasing interest in enacting national electric restructuring legislation, and provisions to enhance or restrict FERC's authority to require RTOs will likely be a featured part of any congressional legislation. 


\section{Bibliography}

Abe, J.; Alexander, L.; Blair, R.; Clark, C.; Hawryluk, C.; Reiss, R.; and Rothstein, S. 2000 United States Regional Transmission Organization Study. Boston: Environmental Futures Inc., 2000.

AWEA 2001. "Wind Energy Projects in the U.S." (Last modified November 13, 2001). American Wind Energy Association on-line, http://www.awea.org/projects/index.html. Accessed November 17, 2001.

AWEA 2000. Fair Transmission Access for Wind: A Brief Discussion of Priority Issues. (Last modified October 16, 2001). American Wind Energy Association on-line, http://www.awea.org. Accessed October 23, 2001.

Bolinger, Mark; Wiser, Ryan; Milford, Lew; Stoddard, Michael; and Porter, Kevin. Clean Energy Funds: An Overview of State Support for Renewable Energy. Lawrence Berkeley National Laboratory on-line, http://eetd.lbl.gov/ea/EMS/ems_pubs.html\#RE. Accessed November 30, 2001.

Brown, Andrew; Ellison, Christopher; Porter, Kevin. Transmitting Wind Energy: Issues and Options in Competitive Electric Markets. (Last modified October 18, 2001). National Wind Coordinating Committee on-line, http://www.nationalwind.org/pubs/default.htm. Accessed October 23, 2001.

Caldwell, J. (2001). (Last modified August 9, 2001). Testimony Before the U.S. Senate Subcommittee on Water Power on Electric Transmission Infrastructure and Investment Needs. American Wind Energy Association on-line, http://www.awea.org/news/new010809trn.html. Accessed September 6, 2001.

Detroit Edison 2001. (Last modified September 7, 2001). "DTE Energy Joins Midwest ISO." Detroit Edison on-line, http://www.dteenergy.com/pressRoom/pressReleases/MISO.html. Accessed September 13, 2001.

Electric Utility Week 2001. “Alliance RTO Hits Rocky Patch at DTE Departs and Groups Mount Challenges." (September 10, 2001); p. 3-4.

Ellison, Chris; Brown, Andrew; Rader, Nancy. Wind Energy System Operation and Transmission Issues Related to Restructuring. (Last modified October 18, 2001). National Wind Coordinating Committee on-line, http://www.nationalwind.org/pubs/default.htm. Accessed October 23, 2001.

ERCOT 2001a. ERCOT: The Market Guide. Taylor, Texas: ERCOT, February 22, 2001. 
ERCOT 2001b. ERCOT Protocols. (Last modified October 1, 2001). ERCOT on-line, http://www.ercot.com/tac/retailisoadhoccommittee/protocols/keydocs/draftercotprotocols.htm Accessed October 24, 2001.

FERC 1996. Promoting Wholesale Competition Through Open Access Non-discriminatory Transmission Services by Public Utilities and Recover of Stranded Costs by Public Utilities and Transmitting Utilities, Order No. 888, 61 Federal Register 21,540 (May 10, 1996), FERC Statutes and Regulations, Regulations Preambles January 1991-June 1996 | 31,036 (1996).

FERC 1997. Order Conditionally Accepting Open Access Transmission Tariff and Power Pool Agreements, Conditionally Authorizing Establishment of an Independent System Operator and Disposition of Control Over Jurisdictional Facilities, And Denying Rehearings, 81 ๆ FERC 61,257.

FERC 1998. Order Conditionally Authorizing Establishment of Midwest Independent Transmission System Operator and Establishing Hearing Procedures, 84 FERC 9 61,231. (Last modified October 23, 2001). Midwest Independent System Operator online, http://www.midwestiso.org/documents/19980916.pdf. Accessed October 26, 2001.

FERC 2000a. Order Accepting Proposed Tariff Revisions for Filing, as Modified, 90 FERC \ 61,015. (Last modified October 4, 2001). New York Independent System Operator online, http://www.nyiso.com/services/documents/filings/index.html. Accessed October 5, 2001.

FERC 2000b. Regional Transmission Organizations, Order No. 2000, 65 Federal Register 809 (January 6, 2000), FERC Statutes and Regulations 931,089 (2000).

FERC 2001a. Order on Settlement Agreement, 95 FERC \ 61,183, May 8, 2001.

FERC 2001b. Letter Order of July 25, 2001, Docket No. ER01-2251-000, 96 FERC \ 61,112. (Last modified October 4, 2001). New York Independent System Operator online, http://www.nyiso.com/services/documents/filings/index.html. Accessed October 5, 2001.

FERC 2001c. Order Accepting Tariff Revisions and Directing Translation of the In-City Price Cap, 96 FERC 9 61,251. (Last modified October 4, 2001). New York Independent System Operator online, http://www.nyiso.com/services/documents/filings/index.html. Accessed October 5, 2001.

FERC 2001d. Order Initiating Mediation, Docket No. RT01-99-000. (Last modified September 17, 2001). FERC online, http:/www.ferc.fed.us/Electric/RTO/rto/issuance/rt01-99-000july.pdf. Accessed July 17, 2001.

FERC 2001e. Administrative Law Judge Mediator's Report to the Commission, Docket No. RT01-99-000. (Last modified September 17, 2001). FERC online, http://www.ferc.fed.us/Electric/RTO/rto/issuance/RT01-991-9-17.pdf. Accessed September 20, 2001. 
FERC 2001f. Business Plan for the Development and Implementation of a Single Regional Transmission Organization for the Northeastern United States. (Last modified September 17, 2001). FERC online, http://www.ferc.fed.us/Electric/RTO/rto/issuance/northeast/rto_biz_plan.pdf. Accessed September 20, 2001.

FERC 2001g. Standardizing Generator Interconnection Agreements and Procedures: Advanced Notice of Proposed Rulemaking. (Last modified December 21, 2001). FERC online, http://cips.ferc.gov/Q/CIPS/RULES/RM/RM02-1.000.TXT. Accessed December 24, 2001.

FERC 2001h. Order Granting RTO Status and Accepting Supplemental Filings, 97 FERC 9 61,326. (Last modified December 21, 2001). FERC online, http://cips.ferc.gov/Q/CIPS/ELECTRIC/RT/RT01-87.00B.TXT. Accessed December 24, 2001.

FERC 2001i. Order on Requests for Rehearing, 97 FERC $₫$ 61,327. Last modified December 21, 2001). FERC online, http://cips.ferc.gov/Q/CIPS/ELECTRIC/RT/RT01-88.00W.TXT. Accessed December 24, 2001.

FERC 2001j. Order Providing Guidance on Continued Processing of RTO Filings, Docket No. RM01-12-000. (Last modified January 25, 2002). FERC online, http://www.ferc.gov/Electric/RTO/rto/issuance/RM01-12.pdf. Accessed January 25, 2002/

FERC 2001k. Order Announcing the Establishment of State-Federal Regional Panels to Address RTO Issues, Modifying the Application of Rule 2201 in the Captioned Dockets, and Clarifying Order No. 607. (Last modified January 25, 2002). FERC online, http://www.ferc.gov/Electric/RTO/rt02-2-11-9-01.PDF. Accessed January 25, 2002.

FERC 2002a. Order Accepting, in Part, Proposed Revisions, 98 FERC $₫$ 61,076 (Last modified February 8, 2002). FERC online, http://cips.ferc.gov/Q/CIPS/ELECTRIC/ER/ER02484.00A.TXT. Accessed February 8, 2002.

FERC 2002b. Working Paper on Standardized Transmission Service and Wholesale Electric Market Design (Last modified March 15, 2002). FERC online, http://www.ferc.gov/Electric/RTO/mrkt-strct-comments/e-1finalSMD.PDF. Accessed April 16, 2002.

FERC 2002c. Options for Resolving Rate and Transition Issues in Standardized Transmission Service and Wholesale Electric Market Design (Last modified April 10, 2002). FERC online, http://www.ferc.gov/Electric/RTO/mrkt-strct-comments/RM01-12-04-10-02.pdf. Accessed April 16, 2002.

FERC 2002d. Order Accepting in Part and Rejecting in Part Amendment No. 42 and Dismissing Complaint (Last modified March 27, 2002). FERC online, http://cips.ferc.gov/Q/CIPS/ELECTRIC/ER/ER02-922.00A.TXT. Accessed April 16, 2002.

Freeman, M. (April 16, 2002). Personal communication. Exelon Corp. 
Freeman, M. (October 17, 2001). Personal communication. Exelon Corp.

Garza, B. (September 5, 2001). Personal communication. Florida Power \& Light Co.

Grace, R. Analysis of the Impact of ISO-NY Rules on Intermittent Renewable Resources. White Plains, New York: Pace Energy Project, August 1999.

Greffe, R. (2001). 2000 Annual Update on Activities in the ERCOT Wholesale Electricity Market. (Last modified March 16, 2001). Texas Public Utilities Commission online, http://www.puc.state.tx.us/electric/reports/qtlyercot/qtlyercot.cfm. Accessed August 31, 2001.

Hirst 2001a. (September 19, 2001). Personal communication. Hirst Consulting.

Hirst 2001b. Interactions of Wind Farms with Bulk-Power Operations and Markets. (Last modified February 6, 2002). http://www.ehirst.com/publications.html. Accessed February 11, 2002.

ISO New England 2002. "Agreement (of the ISO New England and the NYISO)." ISO New England on-line (Last modified January 29, 2002). http://www.isone.com/iso news/nyiso ne agreement.pdf. Accessed January 30, 2002.

ISO New England 2001. Annual Market Report. ISO New England on-line (Last modified December 10, 2001). Available at http://www.isone.com/market_monitoring/Annual_Report_and_Public_Forum/. Accessed December 28, 2001.

ISO New England 2000a. ISO New England on-line (Last modified November 8, 2001)). Available at http://www.iso-ne.com/mrp/MRP11D_Rating and Auditing_NEPOOL_Resources/MRP-11D_Effective_2000-08-01.pdf. Accessed December 18, 2001.

ISO New England 2000b. Elimination of In Service: Business Process Summary, November 2000 .

Lampi 2001a. Lampi, M. Wind Energy Forum, Presentation Before the Wind Energy Forum, Albany, N.Y., July 26, 2001. National Wind Coordinating Committee on-line (Last modified November 16, 2001). Available at http://www.nationalwind.org/summaries/other/nypa/default.htm. Accessed December 5, 2001.

Lampi 2001b. Lampi, M. (December 6, 2001). Personal Communication. New York Independent System Operator.

Letendre, S.; Wooley, D. (Undated draft). NYISO Transmission Tariff Provisions: Creating a Favorable Environment for Wind Power Development in New York.

McCurley, P. (October 25, 2001). Personal communication. ISO New England. 
MA DOER. Massachusetts Division of Energy Resources. Proposed Final Renewable Portfolio Standard Regulations. (Last modified February 6, 2002). MA DOER online, http://www.state.ma.us/doer/home.htm. Accessed February 6, 2002.

McDonald, S. (October 3, 2001). Personal Communication. PG\&E National Energy Co.

Megawatt Daily 2002a. "FERC's Wood to Meet PJM, MISO on Single Market Intentions," Megawatt Daily, January 17, 2002, pp. 1, 9. New York: McGraw-Hill Companies.

Megawatt Daily 2002b. "ERCOT Says Pleased with Transmission Capacity Auction," Megawatt Daily, February 8, 2002, p. 9. New York: McGraw-Hill Companies.

Megawatt Daily 2001. Megawatt Daily 2000 Annual Price Issue. New York: Financial Times Energy.

MW ISOa. Midwest Independent System Operator. Order No. 2000 Supplemental Compliance Filing. (Last modified August 31, 2001). Midwest Independent System Operator online, http://www.midwestiso.org/ferc filings.shtml. Accessed September 10, 2001.

MW ISOb. Midwest Independent System Operator. MISO Day One Real Time Balance. (Last modified August 31, 2001). Midwest Independent System Operator online, http://www.midwestiso.org/ferc_filings.shtml. Accessed September 13, 2001.

MW ISOc. Midwest Independent System Operator. Order No. 2000 Compliance Filing. Docket No. RT01-87-000. Midwest Independent System Operator online, http://www.midwestiso.org/ferc filings.shtml. Accessed September 13, 2001.

MW ISOd. Midwest Independent System Operator. Midwest ISO's Zonal Pricing. (Last modified February 6, 2002). Midwest Independent System Operator online, http://www.midwestiso.org/news/Jan_31_2002_zonal_pricing.pdf. Accessed February 7, 2002.

MW ISOe. Midwest Independent System Operator. Status Report of the Midwest Independent System Operator Inc. (Last modified October 23, 2001). Midwest Independent System Operator online, http://www.midwestiso.org/ferc filings.shtml. Accessed October 25, 2001.

MW ISOf. Midwest ISO Suspension of the Effective Date for Schedule 4 (Energy Imbalance Service and Inadvertent Interchange Service). (Last modified December 28, 2001). Midwest Independent System Operator online, http://www.midwestiso.org/documents/2001/transmittal_letter011130.pdf. Accessed December $28,2001$.

NEPOOL. NEPOOL Open Access Transmission Tariff: General Business Practices.

NEPOOL 1999. Standard Bilateral Transaction Definitions, Chapter 12, July 14, 1999. 
NJ BPU 2001. Subchapter 8, N.J.A.C. 14:4-8, Interim Renewable Energy Portfolio Standards, 2001.

Northeast Utilities 2001. Open Access Transmission Service Rates, Non-Firm Point-To-Point Transmission Service Over Non-PTF Transmission Facilities. (Last modified unknown). Northeast Utilities on-line, http://www.nu.com/ebb2/power/ratesum.asp. Accessed December $11,2001$.

NWCC 2000. Transmission Policy and Pricing in Texas (Transmission Case Study \#1). (Last modified October 18, 2001). National Wind Coordinating Committee online, http://www.nationalwind.org/pubs/default.htm. Accessed October 23, 2001.

NYISO 2002. New York Independent System Operator Monthly Report, January 2002. (Last modified April 15, 2002). New York Independent System Operator online, http://www.nyiso.com/services/documents/mthly-reports/index_mthly-report.html. Accessed April 17, 2002.

NYISO 2001a. Request to Implement a Stage II ICAP Market with an Unforced Capacity Methodology and One-Month Obligation Procurement Period and Request for an Expedited, 10 Business Day Period for Filing on the Issue of the Translation of the \$105 Price Cap for In-City Mitigated Units. (Last modified October 4, 2001). New York Independent System Operator online, http://www.nyiso.com/services/documents/filings/index.html. Accessed October 5, 2001.

NYISO 2001b. Filing of Tariff Revisions to Modify Rules Governing Regulation and Frequency Response Service, Uninstructed Overgeneration and Persistent Undergeneration. (Last modified October 4, 2001). New York Independent System Operator online, http://www.nyiso.com/services/documents/filings/index.html. Accessed October 5, 2001.

NYISO 2001c. Request to Submit Compliance Filing One Day Out of Time and Compliance Filing on Regulation Penalty Exemptions, Docket No. ER01-2251-000. (Last modified October 4, 2001). New York Independent System Operator online, http://www.nyiso.com/services/documents/filings/index.html. Accessed October 5, 2001.

NYISO 2001d. Summer Capability Period ICAP Requirements. (Last modified September 19, 2001). New York Independent System Operator online, http://www.nyiso.com/services/documents/filings/index.html. Accessed October 5, 2001.

NYISO 2001e. NYISO Installed Capacity Manual. (Last modified December 14, 2001). New York Independent System Operator online, http://www.nyiso.com/services/documents/filings/index.html. Accessed December 17, 2001.

NYISO 2001f. New York Independent System Operator Market Administration and Control Area Services Tariff. (Last modified December 14, 2001). New York Independent System Operator online, http://www.nyiso.com/services/documents/filings/pdf/services tariff/services tariff.pdf. Accessed December 17, 2001. 
NYISO 2001g. New York Independent System Operator Monthly Report, December 2001. (Last modified February 6, 2002). New York Independent System Operator online, http://www.nyiso.com/services/documents/mthly-reports/index_mthly-report.html. Accessed February 7, 2002.

NYISO 2000a. Technical Bulletin \#42: Regulation Penalty Calculation for a Generator. (Last modified September 20, 2001). New York Independent System Operator online, http://www.nyiso.com/services/documents/techbulletins/index.html\#41 45. Accessed October 5, 2001.

NYISO 2000b. Technical Bulletin \#16: Rules to Provide PURPA Contract Parties, Certain Intermittent Resources and Certain NYC Steam Turbines an Interim Deferral from Billing for Regulation Performance Penalties. (Last modified September 20, 2001). New York Independent System Operator online, http://www.nyiso.com/services/documents/techbulletins/index.html\#16 20. Accessed October $5,2001$.

NYISO 1999. ISO Open Access Transmission Tariff: Annual Transmission Revenue Requirement for Point-to-Point Transmission Service and Network Integration Service (Attachment H). (Last modified December 3, 2001). New York Independent System Operator online, http://www4.nyiso.com/services/documents/filings/pdf/oatt/oatt_att h h new.pdf/. Accessed December 11, 2001.

NYSEG 2000. New York State Electric \& Gas Service Classification No. 10, May 1, 2000.

Ott, A. PJM Energy Market Model. Presentation before FERC Standard Market Design Technical Conference. (Last modified February 7, 2002). FERC online, http://www.ferc.gov/Electric/RTO/mrkt-strct-comments/rm01-12-comments.htm. Accessed February 7, 2002.

PJM 2002a. "PJM, MISO Planning Joint and Common Wholesale Energy Market" (Last modified January 24, 2002). PJM Online, http://www.pjm.com. Accessed January 25, 2002.

PJM 2002b. PJM Approved Members. (Last modified April 2, 2002). PJM Online, http://www.pjm.com. Accessed April 16, 2002.

PJM 2001a. PJM Interconnection State of the Market Report 2000. (Last modified October 19, 2001). PJM Online, http://www.pjm.com. Accessed July 6, 2001.

PJM 2001b. About PJM Today. (Last modified October 23, 2001). PJM Online, http://www.pjm.com. Accessed October 23, 2001.

PJM 2000. PJM Interconnection State of the Market Report 1999. (Last modified October 19, 2001). PJM Online, http://www.pjm.com. Accessed September 12, 2000. 
Parsons, B (2000). Wind Energy Costs: What is the Range? Presentation before the UWIG/TVP/WPA Workshop, Morgantown, W. Va., October 24-25, 2000.

Parsons, B. (1998). Grid-Connected Wind Energy Technology: Progress and Prospects. Presented at the North American Conference of the International Association of Energy Economists, Albuquerque, N.M., October 18-21, 1998. (Last modified unknown). NREL Online, http://www.nrel.gov/docs/fy99osti/25692.pdf. Accessed December 27, 2001.

Porter, K (2000). Biomass Power and State Renewable Energy Policies Under Electric Industry Restructuring, National Renewable Energy Laboratory, NREL/CP-620-28747, conference paper for Bioenergy 2000, Buffalo, NY, October 15-19, 2000.

Porter, K. (1996). Open Access Transmission and Renewable Energy Technologies, NREL/SP460-21427. (Last modified December 17, 2001). NREL Online, http://www.nrel.gov/analysis/emaa/open access/. Accessed December 19, 2001.

Porter, K. (1995). A Summary of the California Public Utilities Commission's Two Competing Electric Utility Restructuring Proposals, NREL/TP-461-8330, November 1995. Golden, CO: NREL.

Quinlan, M. (December 11, 2001). Personal Communication. Connecticut Department of Public Utility Control.

Short, W. (October 19, 2001). Personal communication. Ridgewood Power Corp.

Siegrist, H. (October 22, 2001). Personal communication. Mirant Power Corp.

Simonelli, J. (October 25, 2001). Personal communication. ISO New England.

Sloan, M. (2001). Texas Renewables 2001: A Very Good Year, Presentation Before the Sixth National Green Power Marketing Conference, July 30, 2001, Portland, Oregon. Available online at http://www.eren.doe.gov/greenpower/gpmc_pres/6gpmc01/msloan01.pdf.

Stoft, S.; Webber, C.; Wiser, R. Transmission Pricing and Renewables: Issues, Options and Recommendations. (Last modified August 2001). Ernest Orlando Lawrence Berkeley National Laboratory Electricity Market Studies on-line, http://eetd.lbl.gov/ea/EMS/ems pubs.html\#RE. Accessed October 23, 2001.

Tannenbaum, M. (December 11, 2001). Personal communication. Maine Public Utilities Commission.

Volpe, M. (September 12, 2001). Personal communication. Midwest Independent System Operator.

Western Governors Association. Conceptual Western Transmission Plan: A White Paper Requested by Western Governors, June 2001. 
Wiese, S. (2001). RTO Update \#4 of 2001. (Last modified August 9, 2001). National Wind Coordinating Commission online, http://www.nationalwind.org/rto/briefings/br01-04.htm. Accessed August 31, 2001.

Wiese, S. (2000a). RTO Update \#3 of 2000. (Last modified August 9, 2001). National Wind Coordinating Commission online, http://www.nationalwind.org/rto/briefings/br03.htm. Accessed August 31, 2001.

Wiese, S. (2000b). RTO Update \#2 of 2000. (Last modified August 9, 2001). National Wind Coordinating Commission online, http://www.nationalwind.org/rto/briefings/br02.htm.

Accessed August 31, 2001. 


\section{Appendix A: FERC's Required RTO Characteristics and Functions in Order 2000}

\section{RTO Characteristics}

1. Independence: RTOs must be independent of market participants. Direct ownership in a RTO, such as a transco, is limited to $5 \%$ of voting securities for a single market participant, and to $15 \%$ collectively for all market participants. All ownership interests that include voting securities must be phased out within five years.

2. Scope and Regional Configuration: RTOs must encompass a region of sufficient scope and configuration as to include all or most of the facilities in a transmission region.

3. Operational Authority: The RTO must be the security coordinator and have the authority to control transmission facilities.

4. Short Term Reliability: The RTO must have sole authority for maintaining the short-term reliability of the grid, as well as receiving, confirming and implementing all interchange schedule. RTOs must also be able to order the redispatch of any generator and approve transmission maintenance schedules.

\section{RTO Functions}

1. Tariff Administration and Design: An RTO must be the only transmission service provider and administrator of its open access transmission tariff. RTOs also must have authority to approve or deny requests for transmission service, as well as requests for new interconnections.

2. Congestion Management: RTOs must work on the development and operation of market mechanisms for congestion management. The RTO will have one year after it begins operating to design and implement a congestion management mechanism.

3. Parallel Path Flows: An RTO will have three years after commencing operations to adopt procedures for addressing loop flow within its region and with other regions.

4. Ancillary Services: RTOs must be the provider of last resort for ancillary services and have the authority to determine the required minimum amounts of each ancillary service. The ancillary services must be included in the open access transmission tariff. Market participants must have the option of self-supplying or acquiring ancillary services from other parties, and have access to a realtime balancing market that is operated by an RTO or by another entity.

5. OASIS (Open Access Service Information System): RTOs must be the single OASIS site administrator for all transmission facilities under the RTO's control, although the actual functions can be contracted to another entity. RTOs must independently calculate total transmission capability and available transmission capability.

6. Market Monitoring: An RTOs is required to objectively monitor the markets it operates to identify design flaws, potential market power, and possible market efficiency improvements, and suggest possible actions. FERC may revisit their requirements for market monitoring as RTOs become operational.

7. Planning and Expansion: RTOs are responsible for planning and directing transmission expansion and upgrades. RTOs must encourage market-based congestion mitigation strategies and work to facilitate multi-state agreements to review and approve new transmission agreements. An RTO must file a schedule with FERC indicating it will meet these milestones within three years of commencing operations.

8. Interregional Coordination: RTOs must coordinate with other RTOs and other regions, and work to integrate reliability and market practices across RTOs and other regions.

Source: Western Governors Association. Conceptual Western Transmission Plan: A White Paper Requested by Western Governors, June 2001. 


\section{Appendix B: Summaries of the PJM, ERCOT and Midwest ISOs ${ }^{20}$}

\section{Pennsylvania-New Jersey-Maryland Interconnection ISO (PJM)}

PJM operates the largest centrally dispatched control area in North America and the third largest in the world. PJM is the nation's first operating ISO, having established operations in January 1998, after receiving FERC approval in November 1997 (FERC 1997).

PJM recently incorporated the transmission facilities of Allegheny Power that comprise PJM West. With those facilities, PJM now includes over 13,000 miles of high voltage transmission lines and over 66,000 MW of generating capability, making PJM the third largest grid in the world. ${ }^{21}$ PJM has a peak load of 62,443 MW (Ott 2002).

PJM operates an integrated open access transmission system and a central energy market. PJM administers the open access transmission tariff; operates the central energy market, regulation, and capacity credit markets; and oversees the day-to-day operation of the bulk power system of the PJM control area.

PJM has 199 members as of April 2002 (PJM 2002b). To become a member, an entity must comply with the PJM operating agreement and be a transmission owner within the PJM control area or an eligible customer under the PJM tariff; a generation owner, supplier, electric distributor, or end-user customer; or an entity that will buy, sell or transmit electric power in or through the PJM.

Transmission pricing varies by zone, with ten zones corresponding to the transmission owners' retail service territories. PJM is required to file a single-rate, single-zone transmission rate with FERC by July 2002 but is expected to ask FERC for a delay. Transmission customers also must pay for line losses, assigned as 3\% of the energy transaction for on-peak hours and $2.5 \%$ for off-peak hours. Point-to-point transmission customers can self-supply losses if their transmission reservation exceeds $200 \mathrm{MW}$.

Energy Markets: PJM administers a spot energy market in addition to its open access transmission tariff. In June 2000, PJM adopted a two-settlement market consisting of a dayahead energy market and the real-time energy market. Previously, PJM's energy market was only one settlement, i.e., a real-time energy market.

In 1999, the PJM energy market averaged about 30,000 MW per hour. Of this, the spot energy market represented 4,500 MWh or 15\%; the bilateral market encompassed about 9,000 MWh per hour or about 30\%. Net imports were about $500 \mathrm{MWh}$ per hour. The rest of the energy supply (about 55\%) was self-supplied by LSEs, primarily by utilities that own generation

\footnotetext{
${ }^{20}$ No material is presented in this Appendix on the NYISO - all of the explanatory material on the NYISO is in the main report.

${ }^{21}$ The only two larger centrally dispatched grid entities are Electricitie de France and Tokyo Electric (PJM 2001b).
} 
resources and serve electric load. The PJM energy spot market prices in 2000 were less than $\$ 20 / \mathrm{MWh}$ in about $51 \%$ of the hours; less than $\$ 30 / \mathrm{MWh}$ in $70 \%$ of the hours; less than $\$ 40 / \mathrm{MWh}$ in $80 \%$ of the hours; less than $\$ 60 / \mathrm{MWh}$ in $91 \%$ of the hours and less than $\$ 80 / \mathrm{MWh}$ in $98 \%$ of the hours (PJM 2001a).

Market participants in PJM's day-ahead market must submit the amount and location of customer load or energy purchases by noon of the day before, for each hour of the next operating day. Buyers can specify the price at which it does not wish to include its load in the energy market rather than pay the day-ahead market price. Similarly, market sellers in the day-ahead market can submit offers to sell energy, regulation, operating reserves or other ancillary services for the next operating day. Energy supply bids to PJM can come from inside or outside PJM, although resources from outside PJM must make their own transmission arrangements to transmit power into PJM. All sellers in the day-ahead market are paid a single price at each hour, i.e., the highest bid price accepted by PJM to serve load at that hour. Bids for providing energy are capped at $\$ 1000$ per $\mathrm{MWh}$, and bids for providing regulation are capped at $\$ 100$ per MWh.

The parties to bilateral transactions must notify the PJM of these transactions, and whether they are to be included in the day-ahead market. The parties also must tell PJM whether they are willing to pay congestion charges, if congestion occurs, and if so, at what price (congestion or energy price) would they want the transaction partly or fully curtailed rather than pay the congestion costs. If they elect to pay the congestion costs, PJM will not curtail their transactions unless there is a system emergency. Other market participants serving load can selfschedule generating resources on an hourly basis. They also must submit a rate to PJM that selfscheduled resources will disconnect or reduce energy output.

Once the PJM posts the initial results of the day-ahead market, a "generation rebidding period" occurs from 4:00 p.m. to 6:00 p.m. in which market participants may change offers for any energy resource that was not selected in the day-ahead market. After that, with an hour's notice market participants can request non-firm transmission; request delivery or receipt of spot market energy; and owners of generating resources with load to serve can self-schedule resources or remove from service resources previously assigned as self-scheduled.

Congestion Management: PJM was the first to propose and receive FERC approval of locational-based marginal pricing (LBMP). LBMP is designed to reflect the marginal cost of electric generation to meet load, and the cost of delivering that energy through transmission.

If there is not any transmission congestion, then the LBMP would be the same at all buses (nodes). With congestion, transmission constraints may keep an inexpensive generator outside the constrained area from serving load within that area during certain hours. When this occurs, a more expensive generator located within the constrained area must be dispatched. While this is essentially the same as redispatch procedures that utilities have always employed, what is different here is that the redispatch costs are charged directly to specific transmission customers, and are incorporated in the price of electricity at the location of the bus. As noted before, PJM market participants can opt to pay these congestion costs and thereby have their transactions completed, or they may have their transactions curtailed. PJM measures LBMP at 
approximately 1,600 nodes, with the cost of supplying energy at each node is calculated every five minutes. PJM integrates these five-minute values into an hourly amount for each node.

For PJM, the lower cost generating resources are disproportionately located in the western portion of the region, and load is disproportionately located in the eastern part of the region. Therefore, energy typically flows from west to east in PJM. With transmission constraints, there are times when expensive generation in the east must be dispatched to serve the local load even though lower cost energy is available for dispatch in the western part of the PJM.

PJM determines two types of congestion costs, reflective of the type of transmission service it offers: point-to-point congestion charges and network service congestion costs. Congestion costs for firm and non-firm point-to-point transmission customers are determined by the difference in LBMP between the generation and delivery buses. Congestion costs for network transmission customers are similarly determined but for the aggregate of all the generation and delivery buses.

Firm point-to-point and network transmission customers can avoid congestion charges by holding or purchasing firm transmission rights (FTRs). A FTR in PJM is essentially a financial right to any congestion revenues in a certain direction from path $\mathrm{A}$ to path $\mathrm{B}$ along a transmission path. FTRs are assigned to firm point-to-point or network transmission customers, or FTRs can be purchased through a monthly PJM auction or through bilateral transactions. FTRs can be a liability as well as a benefit to the FTR holder. Benefits occur when the FTR path is in the same direction as the congested flow, i.e., the LBMP at the source point is greater than the delivery or sink LBMP. FTR holders then receive a credit that counters any congestion charges they may incur for that particular transmission path. If the opposite occurs, then FTRs are a liability for the owner. The FTR holder must pay charges amounting to the difference in LBMP from source to sink, multiplied by the MW amount of the FTR (PJM 2001a).

Capacity Markets: PJM requires load-serving entities to own or purchase an amount of installed capacity resources equal to their load obligations, plus a 19 percent reserve margin. Those not meeting the capacity obligation must purchase capacity credits or pay a capacity deficiency charge of $\$ 58,400 / \mathrm{MW} /$ year. The charge is intended to represent the annual fixed costs of a combustion turbine and any transmission investment and depreciation and fixed O\&M expenses (PJM 2000).

Other than self supply of capacity, Load Serving Entities (LSEs) may purchase capacity resources in three ways. First, LSEs may purchase capacity bilaterally from a source inside the PJM control area. These PJM-internal transactions may be a partial or full capacity purchase in a specific generating unit, or by a capacity credit transaction that represents a unit of unforced capacity measured in MWs of unforced capacity per day. Second, capacity may be purchased from a capacity resource outside the PJM control area, as long as it is from a specific unit and has a firm transmission path to the PJM control area. Finally, capacity resources may be bought from the daily, monthly, or multi-monthly PJM capacity credit market. The capacity credit market is designed to help new entrants in restructured retail electric markets to acquire capacity to meet their peak load plus a reserve margin, and for existing utilities that lose load to new entrants to sell capacity that is no longer needed. The capacity credit market is intended to 
provide a transparent and liquid market for new entrants to buy capacity and allows generation owners to sell surplus capacity.

\section{Electric Reliability Council of Texas (ERCOT) ISO}

The ERCOT ISO operates wholly in the state of Texas and is not subject to FERC jurisdiction. ERCOT encompasses about 200,000 square miles, or $75 \%$ of Texas, and has a summer peak load of about 57,600 MW. There are about 18 million customers in the ERCOT system that account for $85 \%$ of the load in Texas. ERCOT contains 10 interconnected control areas. ERCOT has 12,700 miles of $69 \mathrm{kV}$ transmission lines; 110 miles of $115 \mathrm{kV}$ lines; 17,400 miles of $138 \mathrm{kV}$ lines; and 7,200 miles of $345 \mathrm{kV}$ lines. In August 1996, the PUCT approved an industry-wide filing for transforming ERCOT into an ISO. In June 2001, ERCOT consolidated the 10 control areas into one.

The ERCOT ISO's main responsibilities include maintaining the security of the bulk power system, facilitating the transmission market and energy scheduling, and coordinating transmission planning by transmission owners. Retail competition began in Texas on January 1, 2002, and the ERCOT ISO has four new broad responsibilities:

- Ensure transmission and distribution access for all buyers and sellers on nondiscriminatory terms and conditions.

- Ensure the reliability and adequacy of the transmission system.

- Ensure that information concerning a customer's choice of retail electric providers is transmitted quickly and efficiently.

- Ensure that electricity production and delivery are accurately accounted for among generators, buyers and sellers in ERCOT.

Transmission Services: Prior to January 1, 2002, ERCOT provided two types of transmission service - planned and unplanned. Planned transmission service delivered energy to a specified load from a generating resource. Planned transmission can be acquired on an annual and monthly basis and is paid for by load. Unplanned transmission was for power from resources that are not planned resources and was reserved through the ERCOT Open-Access Same Time Information System (OASIS) for available transmission capacity (ATC), as calculated by ERCOT. There was no charge for unplanned transmission service other than for losses and a 15 cent per MWh scheduling fee to ERCOT, although the length of service could not exceed 30 days (NWCC 2000).

These arrangements changed in January 2002 when retail competition was implemented in Texas, as the distinction between planned and unplanned transmission disappeared. All transmission has the same priority of service. ERCOT's approach relies on bilateral contracts between generators and LSEs. These entities, in turn, communicate via scheduling coordinators, who are the sole entities that communicate with the RTO. ERCOT's protocol contrasts with 
those of the pro forma transmission tariffs in Order 888. There, wholesale transmission customers must reserve point-to-point, firm or non-firm, or network transmission, and then sell to either bilateral customers or to a central energy market.

Transmission Pricing and Interconnection: The ERCOT ISO is operated and priced as a single integrated system, effectively making all transmission service network service. Load in Texas pays for all transmission and ancillary services, except for energy imbalances. Transmission pricing is based a system-wide rate that includes losses and a $22 \mathrm{cent} / \mathrm{MWh}$ scheduling fee to ERCOT. The ERCOT ISO also charges transmission service providers administrative fees.

The access charge for annual transmission service is set for each transmission provider by dividing the provider's annual transmission cost of service by the total load of ERCOT. That, in turn, is multiplied by each transmission customer's peak load to estimate the access charge for each annual transmission service customer.

Transmission can also be extended to hook-up new generation plants, with the costs being borne by all users of the system, rather than directly assigned to the new generators. ERCOT calls this "driveway access" for interconnecting new generators. The combination of this practice and postage stamp transmission rates has made it easier to develop wind projects in western Texas, where the wind resources are especially good, and to build transmission in order to serve load that is predominately in central and eastern Texas (NWCC 2000). FERC has incorporated ERCOT's process of interconnecting new generation plants in an Advance Notice of Proposed Rulemaking as a "straw man" for interconnection procedures nation-wide, as supplemented by best practices outside of ERCOT (FERC 2001g).

Transmission Congestion Pricing: For an interim period, ERCOT is using generation redispatch to alleviate transmission congestion. Market participants are asked to provide generation prices. The ISO then increases generation in the congested transmission service area and curtails generation in the area serving transmission, by economic order. Redispatch costs are allocated by uplift charges to all transmission customers on a load ratio share basis. ERCOT will continue to use re-dispatch until the costs of relieving congestion exceed \$20 million, or by May 2004 at the latest. However, the \$20 million was quickly exhausted, and ERCOT designated four congestion zones-North, South, West and Houston. Scheduling entities are given the opportunity to submit alternative schedules to resolve congestion identified by ERCOT. If congestion continues, ERCOT calls upon replacement reserve and balancing energy to mitigate congested transmission paths. Congestion costs will be assigned to scheduling entities based on their scheduled or actual deliveries over congested interfaces. Local congestion within zones is resolved with balancing energy, and costs are recovered through uplift charges. Scheduling entities can bid specific resources at specific premiums (in $\$ / \mathrm{MWh}$ ) to relieve congestion by increasing or decreasing production.

ERCOT also had its first auction of transmission congestion rights (TCRs) in February 2002. A TCR gives the holder the right to transmit $1 \mathrm{MW}$ of power at any time over a designated transmission constraint between zones. ERCOT will auction off $60 \%$ of available TCRs annually and 40\% monthly (Megawatt Daily 2002b). Auctions will be multi-settlement, 
with successive bids until all available TCRs are assigned to willing buyers. Existing, "grandfathered" contracts will be pre-assigned TCRs based on each entity's load-ratio share of ERCOT redispatch costs from 1997 through 1999. These TCRs will be in effect for three years after the entity begins retail choice, or after federal private use restrictions are eased or removed (ERCOT 2001a).

Imbalance Penalty Provision for Intermittent Renewable Energy Technologies: Intermittent renewables are exempt from scheduling penalties, as long as total metered intermittent renewable resources do not exceed $150 \%$ or is less than $50 \%$ of the intermittent renewable resource's scheduled in any schedule interval. If there are uninstructed deviations beyond the $50 \% / 150 \%$ provision, then scheduling entities either pay or are paid the zonal market clearing price. A separate uninstructed charge back, as a factor of the market clearing price, would be applied to each scheduling entity by each congestion zone where schedule deviations are present (ERCOT 2001b).

\section{Midwest Independent System Operator (Midwest ISO)}

The Midwest ISO presently includes 14 transmission owners and covers an area from North and South Dakota to western Ohio. Overall, the Midwest ISO encompass parts or all of 14 states and parts of three different reliability councils - the East Central Reliability Coordination Agreement (ECAR); the Mid-American Power Pool (MAPP) and the Mid-American Interconnected Network (MAIN). As presently configured, the Midwest ISO would include over 89,000 miles of transmission lines, serve a peak load of 79,800 MW, and have about 84,500 MW of generating capacity (MW ISOe). FERC provisionally approved the Midwest ISO as an RTO under Order 2000 in December 2001 (FERC 2001h).

As presently constructed, the Midwest ISO is a non-stock, not-for-profit corporation with functional control over all network transmission facilities above $100 \mathrm{kV}$ and all network transformers where the two highest voltages exceed $100 \mathrm{kV}$. Unlike the PJM and ERCOT ISOs, the Midwestern ISO would not operate as a single control area. Transmission owners that are currently control area operators would continue to operate their control area for local generation control and economic dispatch. However, the transmission owners would follow the instructions of the Midwest ISO for redispatching generation, curtailing load, and providing reactive supply, voltage control or other ancillary services.

The Midwest ISO is reservations-based, where transmission customers must reserve a specified amount of transmission service-either network, firm or non-firm point-to-point transmission service. Zonal transmission pricing will be used for a transition period of six years after the Midwest ISO begins operations, with transmission pricing set to the control area of each transmission owner in the Midwest ISO. To recover revenues lost from the elimination of transmission rate pancaking, the Midwest ISO adds a fee to regional through-and-out transmission service. 
Transmission owner membership in the Midwest ISO has changed over time. Three of the largest members-Illinois Power Co., Commonwealth Edison and Ameren Corp.-received FERC approval in May 2001 to leave the Midwest ISO in favor of the Alliance RTO, a for-profit transco that covers an area from Ohio to eastern Virginia (FERC 2001a). All three utilities are either located or have facilities in Illinois and comprise the center of the Midwest ISO.

Notwithstanding the departure of the three Illinois utilities, the Midwest ISO is expanding considerably in the future. The Southwest Power Pool and the Midwest ISO announced plans to merge, which would expand the Midwest ISO's territory to parts of the Midwest and the South central region. Four utilities in the Midwest are combining forces with two Midwest ISO transmission owners (Alliant Energy and Xcel Energy) to form TRANSLink, an independent transmission company (ITC) that would operate within the Midwest ISO. Additionally, the proponents of the Crescent Moon RTO that encompasses the upper Midwest and parts of Canada may join Midwest ISO as a member (MW ISOa). Finally, the International Transmission Co., a subsidiary of the Detroit Edison Co., withdrew from the Alliance RTO and joined the Midwest ISO (Detroit Edison 2001).

The changing membership of the Midwest ISO led to a unique set of circumstances, where the boundaries between the Midwest ISO and the Alliance RTO are not only along contiguous borders, but also exist within each RTO. Indeed, two transmission owners in the Midwest ISO - Central Illinois Power Co. and Southern Illinois Power Cooperative - are located entirely within the Alliance RTO. These "holes" in the Midwest ISO have caused some observers to worry about possible transmission scheduling incompatibilities and transmission rate pancaking between the Midwest ISO and the Alliance RTO.

To address some of these concerns, the Midwest ISO and Alliance RTO entered into a settlement agreement whereby the combined region is under a single regional transmission rate for transmission customers that signed onto the agreement as of the end of February 2001 (MW ISOa). The Midwest ISO has indicated it will support requests by transmission customers to be under the regional rate (Volpe 2001). The two RTOs are also working to ensure scheduling compatibilities for transmission customers, and to cooperate on transmission planning, congestion management, market monitoring and generator interconnection. The settlement agreement could be quite beneficial for transmission customers and generators, as it could help create one-stop shopping for transmission service across the Midwest. Multiple charges for accessing both RTOs will not be entirely avoided, as transmission customers will have to pay losses, scheduling fees, reactive power charges, and administrative cost adders to both RTOs for inter-RTO transactions. However, the Midwest ISO believes the sum of these charges will be significantly less than if full transmission and ancillary service charges had to be paid to each RTO (MW ISOa).

Despite these efforts, several stakeholders believed implementation of the settlement agreement was not proceeding as smoothly as represented by the Midwest ISO and the Alliance RTO, and advocated that FERC order that the two organizations be joined in some way. In December 2001, FERC approved the Midwest ISO as an RTO under Order 2000, but also determined that the Alliance RTO does not comply with Order 2000 because of insufficient scope. FERC directed the Alliance RTO to explore joining the Midwest ISO (FERC 2001i). 
Congestion Management: The Midwest ISO's initial congestion management strategy is broken into two phases. The first phase is to facilitate reassignment of transmission capacity, while the second phase is to redispatch generation to maintain existing firm transmission reservations. For the first phase that began in February 2002, transmission customers with firm point-to-point transmission may offer to resell their reservation or entitlements across constrained lines. The Midwest ISO will act as a facilitator by posting bids of available transmission capacity on an electronic bulletin board. If a reassignment occurs, the Midwest ISO receives a fee from the assignee. The assignee will not pay the base transmission rates on file at FERC, but whatever rate is negotiated with the original transmission customer. That customer is still obligated to pay the Midwest ISO for its transmission reservation.

For the second phase, scheduled to begin in May 2002, the Midwest ISO will order generator redispatch to avoid curtailing firm transmission arrangements. Costs of redispatch will be spread among all firm load, with transmission customers paying a part of costs to reimburse the Midwest ISO and the generators. Non-firm transmission customers will be curtailed, unless they are willing to pay the redispatch costs.

Order 2000 requires RTOs to have a market-based congestion management system in place no later than one year after the RTO begins operations. The Midwest ISO is considering a proposal that combines locational-based marginal pricing with capacity rights at certain transmission points, or "flowgates." The goals are to mitigate price congestion costs in real time; to provide for real-time balancing of the transmission system, including a settlement system for balancing costs; and to create a forward market for trading transmission congestion rights.

Under the "hybrid" proposal, the Midwest ISO annually would determine commercially significant flowgates and auction (or allocate, in some way) one-way flowgate rights (FGRs) across these interfaces. FGRs are direction-specific and give parties a right to schedule across a flowgate without incurring congestion costs. Parties can trade or sell FGRs in secondary markets outside the Midwest ISO. Market participants can subdivide their FGRs by time period (weekly, daily, hourly) or by volume (in smaller megawatt units). The Midwest ISO must buy back any FGRs it cannot honor, and the buyback price may be subject to any applicable FERC-approved price caps. The Midwest ISO could add or change the commercially significant flowgates each month, and allocate or auction any additional FGRs for the coming month. A bid-based LBMP, in turn, would be used to determine redispatch costs for mitigating congestion and for creating a real-time balancing market.

The hybrid proposal allows market participants to discover congestion costs in advance and creates easily-traded vehicles for hedging against congestion. The LBMP part of the hybrid proposal gives price signals at certain nodes for short-run market operations such as balancing markets, and for long-run market decisions such as generation siting or transmission investment to alleviate congestion. The LBMP also allows for short-term energy production and consumption without advance scheduling. Transmission customers would not be required to obtain FGRs in advance of scheduling transmission, but those that did would not be exposed to congestion charges in the ISO's real-time settlement process. 
The ISO's real-time settlement would contain two steps. The Midwest ISO would first determine the value of the FGRs using a modeled dispatch on commercially significant flowgates, various grid conditions and certain distribution factors. Then the Midwest ISO would determine the LMBP congestion charges using actual constraints and grid conditions from realtime dispatch.

The hybrid proposal could work well for intermittent renewables by creating a secondary market in transmission rights that would be broken down into hour-by-hour increments, and make transmission rights available for short periods of time. The LBMP would create a penaltyfree energy imbalance market. However, the defections of several utility members of the Midwest ISO in 2000 temporarily shelved discussions on the hybrid proposal (Wiese 2000a). Those discussions have recently resumed, and the Midwest ISO is planning to adopt some version of its hybrid proposal by 2003, pending FERC's efforts to adopt a standard market design for RTOs (MW ISOe).

Transmission Services and Pricing: The Midwest ISO is a reservations-based ISO where transmission customers must reserve a specified amount of transmission service, be it network, firm and non-firm point-to-point transmission service. Zonal pricing will be used for a transition period of six years after the Midwest ISO begins operations. The zones will be set according to the control areas operated by the transmission owners as of when the Midwest ISO filed for approval at FERC in 1998. Transmission customers will be charged the zonal rate based on where the load is located, regardless of whether service is from outside the Midwest ISO to inside the ISO (drive-in service) or point-to-point transmission service within the Midwest ISO (drive-within service). The zonal rates will be set by the fixed and operating costs of the transmission facilities in a zone.

Zonal rates will continue after the transition period unless transmission owners in contiguous zones unanimously agree to combine zones. The Midwest ISO may also revise the rate formula with the agreement of all transmission owners paying ISO transmission service fees for bundled transmission service. The Midwest ISO may also seek regulatory approvals to combine zones, if the following occurs:

- If each of the transmission owners in the zones to be combined paying the ISO for transmission service for load agree to combine zones;

- If transmission owners in contiguous zones paying for transmission service for bundled loads are assured cost recovery for transmission service;

- If there are contiguous zones to be combined with no owners paying the Midwest ISO for transmission service with bundled load.

Alternatively, any transmission owner or owners may agree to combine zones (MW ISOc). 


\section{Appendix C: Midwest ISO Scenario Spreadsheet \\ Midwest ISO and Intermittent Renewables}

\section{BILATERAL AT LOWER SCHEDULED CAPACITY (1/3 and 1/2)}

Assumptions:

\begin{tabular}{|c|c|c|}
\hline Capacity (MW) & & 10 \\
\hline Capacity Factor & & $30 \%$ \\
\hline Expected Price & $\$$ & 45.00 \\
\hline Annual Generation & & 26,280 \\
\hline $3 \%$ Losses & & 788 \\
\hline Generation Net of Losses & & 25,492 \\
\hline 1/3 Generation Bid & & 8,412 \\
\hline 1/2 Generation Bid & & 12,746 \\
\hline Cinergy 2000 Average Spot Market Price & $\$$ & 26.05 \\
\hline
\end{tabular}

\section{Generator at $1 / 3$ Bid}

Target Breakeven Point

Actual Revenues

MW ISO Membership Fee

Hourly Non-Firm Transmission

MW ISO Schedule 10 Fee

MW ISO Schedule 1 Fee

MW ISO Schedule 2 Fee

MW ISO Schedule 14 Fee (ZTA)

Energy Sales to Real-Time Spot Market

Net Revenue

Policy/Green Marketing Revenues

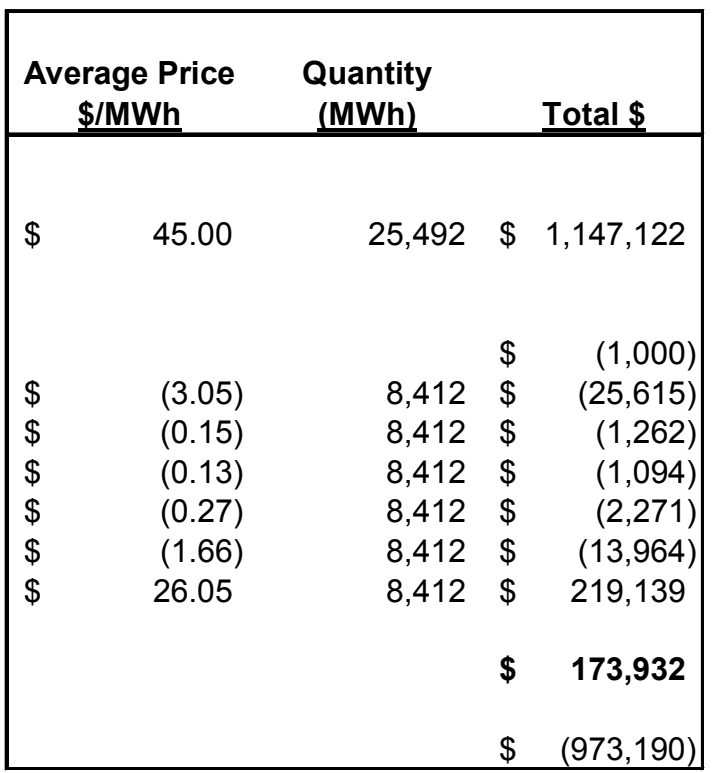

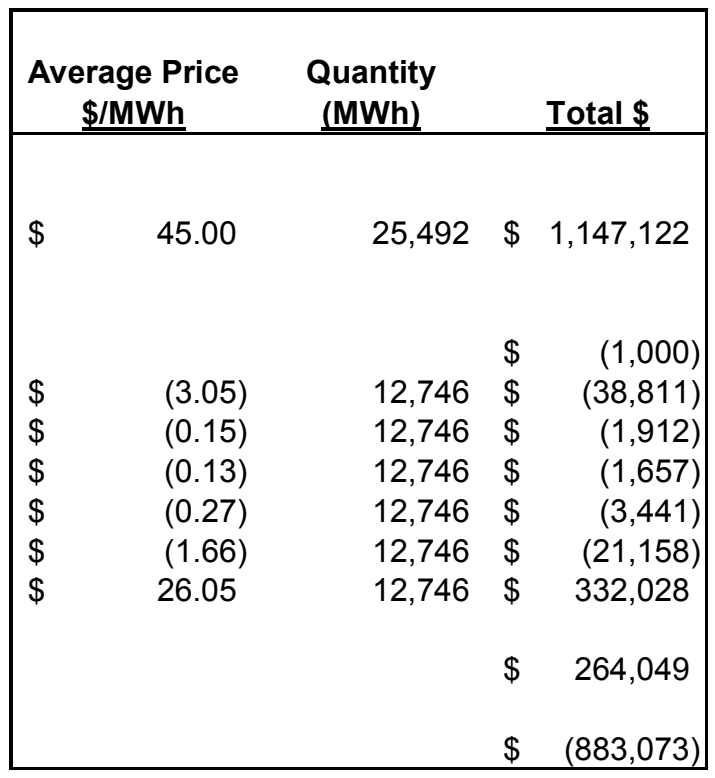

\section{Generator at $1 / 2$ Bid}

Target Breakeven Point

Actual Revenues

MW ISO Membership Fee

Hourly Non-Firm Transmission

MW ISO Schedule 10 Fee

MW ISO Schedule 1 Fee

MW ISO Schedule 2 Fee

MW ISO Schedule 14 Fee (ZTA)

Energy Sales to Real-Time Spot Market

Net Revenue

Policy/Green Marketing Revenues 


\section{Midwest ISO and Intermittent Renewables}

\section{NON-FIRM BILATERAL TRANSACTION}

\section{Assumptions:}

Capacity (MW)

Capacity Factor

10

Expected Price

Annual Wind Generation

$3 \%$ Losses

Wind Generation Net of Losses

Wind Generation on Schedule

Wind Generation Under-Delivery

Wind Generation Over-Delivery

Total Need for Customer

Need Minus Wind Generation

Cinergy 2000 Average Spot Market Price

$\begin{array}{rr} & 10 \\ & 30 \% \\ \$ \quad 45.00 \\ 26,280 \\ 788 \\ 25,492 \\ 8,497 \\ 8,497 \\ 8,497 \\ \\ \\ \\ \\ \\ & 61,724 \\ \text { \$ } \quad 232 \\ & 26.05\end{array}$

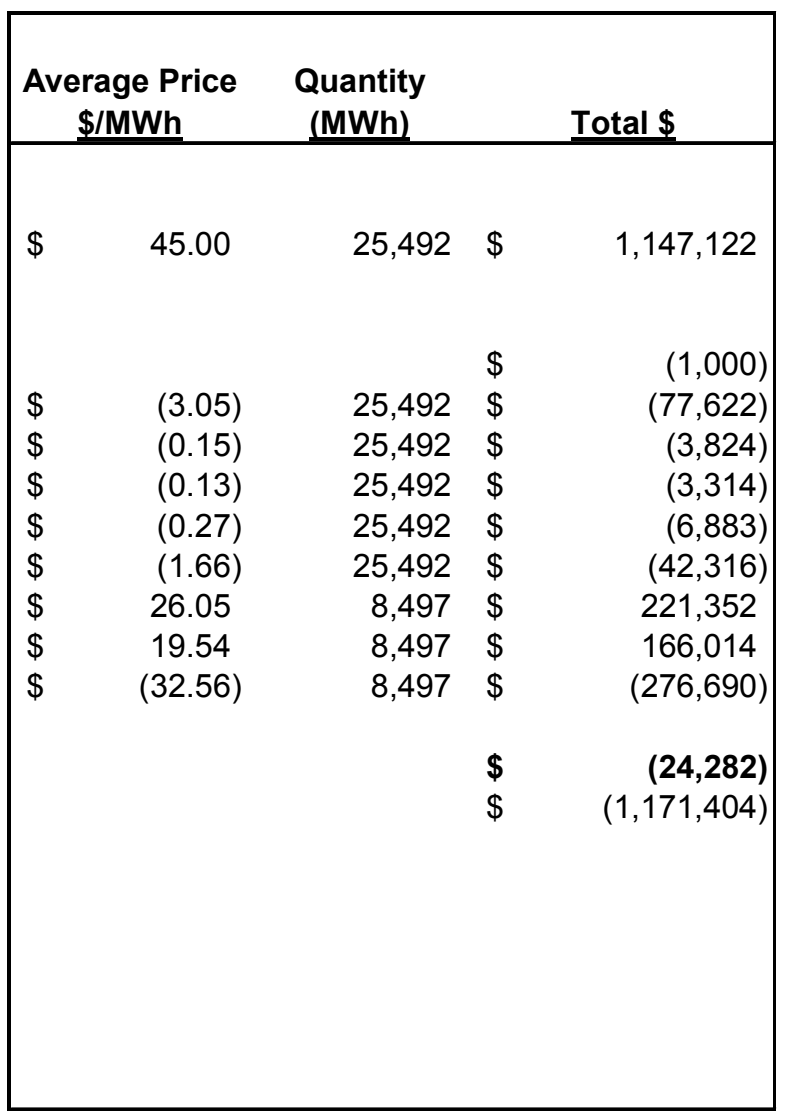




\section{Midwest ISO and Intermittent Renewables \\ BILATERAL CONTRACT \\ (INTERMITTENT BUNDLED WITH OTHER SOURCES)}

Assumptions:

Capacity (MW)

Capacity Factor

Expected Price

Annual Wind Generation

$3 \%$ Losses

Wind Generation Net of Losses

Cinergy 2000 Average Spot Market Price

$$
\begin{array}{rr} 
& 10 \\
& 30 \% \\
\$ \quad 45.00 \\
26,280 \\
788 \\
\\
25,492 \\
\$ \quad 26.05
\end{array}
$$

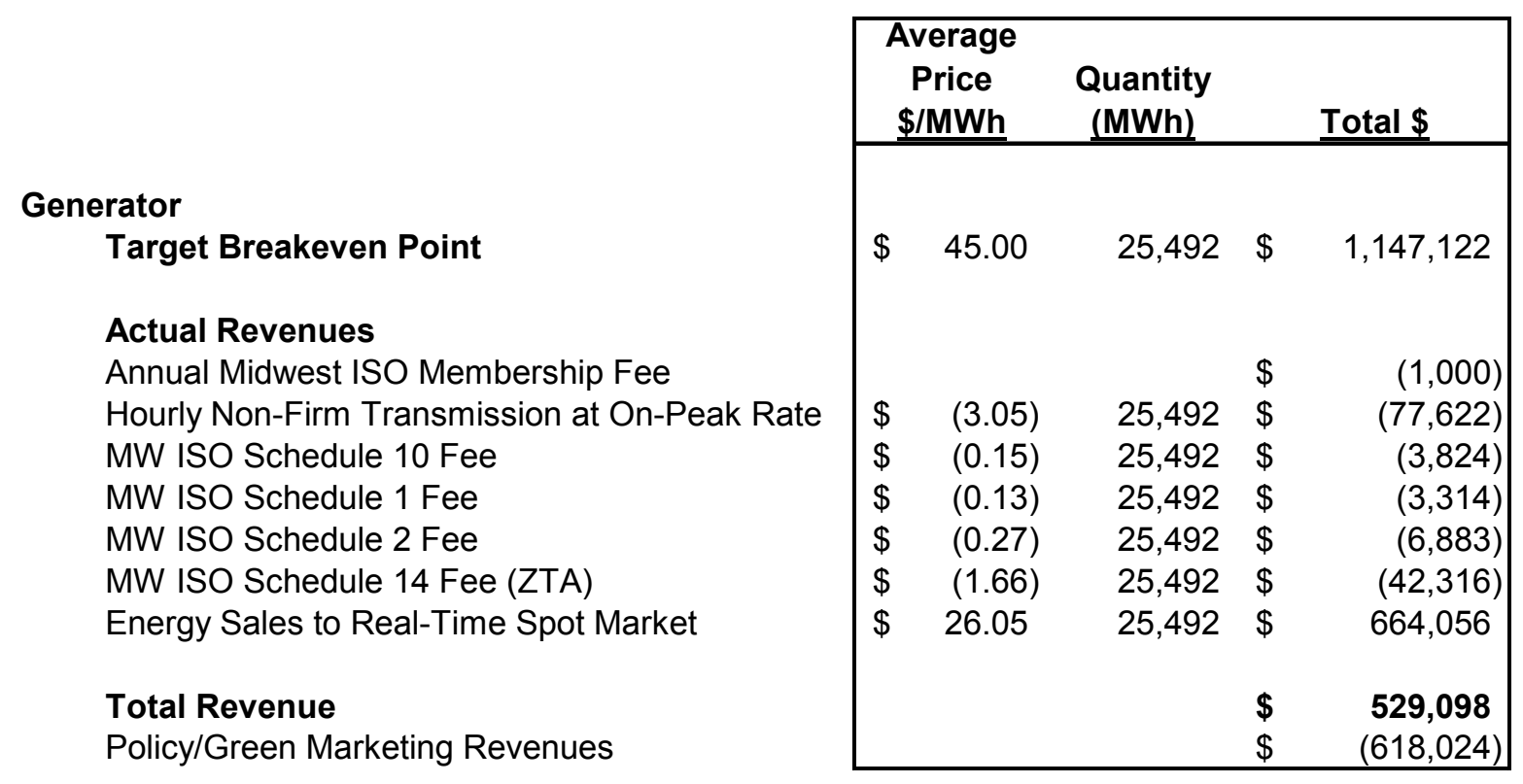




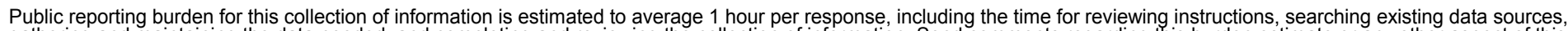

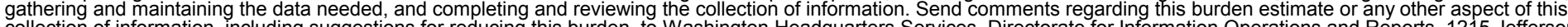
this burden, to Washington Headquarters Services, Directorate for Information Operations and Reports, 1215 Jefferson Davis Highway, Suite 1204, Arlington, VA 22202-4302, and to the Office of Management and Budget, Paperwork Reduction Project (0704-0188), Washington, DC 20503.

\begin{tabular}{|l|l|l} 
1. AGENCY USE ONLY (Leave blank) & $\begin{array}{l}\text { 2. REPORT DATE } \\
\text { May } 2002\end{array}$ & $\begin{array}{l}\text { 3. REPORT TYPE AND DATES COVERED } \\
\text { Subcontractor Report - Analysis }\end{array}$
\end{tabular}
4. TITLE AND SUBTITLE
The Implications of Regional Transmission Organization Design for Renewable Energy
Technologies

6. $\operatorname{AUTHOR}(\mathrm{S})$

Kevin Porter

7. PERFORMING ORGANIZATION NAME(S) AND ADDRESS(ES)

Exeter Associates

12510 Prosperity Drive, Suite 350

Silver Spring, MD 20904

9. SPONSORING/MONITORING AGENCY NAME(S) AND ADDRESS(ES)

National Renewable Energy Laboratory

1617 Cole Blvd.

Golden, CO 80401-3393
5. FUNDING NUMBERS

C: KADC-9-29462-08

TA: AS72-1006

8. PERFORMING ORGANIZATION REPORT NUMBER

11. SUPPLEMENTARY NOTES

NREL Technical Monitor: Larry Goldstein

12a. DISTRIBUTION/AVAILABILITY STATEMENT

National Technical Information Service

12b. DISTRIBUTION CODE

U.S. Department of Commerce

5285 Port Royal Road

Springfield, VA 22161

ABSTRACT (Maximum 200 word). This report summarizes the development of Regional Transmission Organizations (RTOs) and assesses the potential implications of market rules for renewable energy technologies. The report focuses on scheduling provisions, as these have proved problematic in some cases for intermittent renewable energy technologies. Market rules of four RTOs-the Pennsylvania-Maryland-New Jersey ISO, the ERCOT ISO, the Midwest ISO and the New York ISO (NYISO)-were examined to determine the impact on intermittent renewable energy projects such as wind energy generators. Also, a more general look was taken at how biomass power may fare in RTOs, specifically whether these technologies can participate in ancillary service markets. Lastly, an assessment was made regarding the implications for renewable energy technologies of a Northeast-wide RTO that would combine the three existing Northeast ISOs (the aforementioned PJM and NYISOs, as well as ISO New England).

14. SUBJECT TERMS

Regional Transmission Organization; RTO; FERC; transmission; Exeter Associates; Kevin Porter; renewable energy; Pennsylvania-New Jersey-Maryland Interconnection ISO; PJM; Midwest ISO; New York ISO; biomass power

17. SECURITY CLASSIFICATION OF REPORT

Unclassified
18. SECURITY CLASSIFICATION OF THIS PAGE Unclassified
19. SECURITY CLASSIFICATION OF ABSTRACT Unclassified
15. NUMBER OF PAGES

16. PRICE CODE

20. LIMITATION OF ABSTRACT

UL 